\title{
Articulación interestatal en la gestión de residuos sólidos urbanos. El caso de los Municipios entrerrianos
}

\author{
Interstate articulation for the nanagement of urban solid waste. \\ The case of local governments in Entre Ríos \\ Articulação entre nação, província e município na gestão de resíduos \\ sólidos urbanos. O caso dos Municípios entrerrianos
}

\author{
Mauricio Bach \\ Facultad de Ciencias Económicas, \\ Universidad Nacional del Litoral, Argentina. \\ E-mail:mauriciojbach@gmail.com
}

Fecha de recepción: 10/04/2017 Fecha de aceptación: 15/06/2017

Palabras clave

- Diseño

- Formulación

- Implementación

- Políticas Ambientales

- Gestión de Residuos

\section{Resumen}

En este trabajo se intenta indagar sobre el diseño, la formulación y la implementación en los municipios de la Provincia de Entre Ríos del "Plan Provincial de Gestión Integral de Residuos Urbanos de Entre Ríos". Para ello, en una primera instancia, se definen los objetivos e hipótesis a comprobar; se continúa con la revisión del estado del arte en la temática seleccionada, del material bibliográfico, de las entrevistas a informantes claves y la documentación relacionada con el objeto de esta investigación. Con posterioridad, se intentan verificar las hipótesis planteadas, para lo cual se describe y analiza el diseño y la implementación de la política de gestión integral de residuos urbanos y, por último, se enuncian algunas conclusiones.

\footnotetext{
Abstract

This article is an attempt to investigate the design, formulation and implementation of the "Provincial Plan for the Integral Management of Urban Waste in Entre Ríos" in the local governments of Entre Ríos. To do this, the objectives and hypotheses to be tested are defined firstly. Secondly, the state-of- the-art in the selected topic, the bibliographic material, interviews
} 


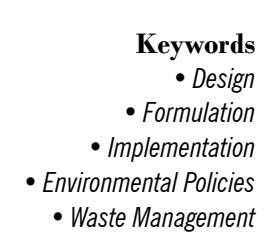

Palavras-chave

- Desenho

- Formulação

- Implementação

- Políticas Ambientais

- Gestão de Resíduos with key informants and the documentation related to the object of study of this research are reviewed. Subsequently, the design and implementation of the policy of integral management of urban waste are described and analyzed in an attempt to verify the hypotheses stated. Finally, some conclusions are outlined.

\section{Resumo}

0 presente trabalho tenta indagar sobre 0 desenho, formulação e implementação nos municípios da Província de Entre Rios do "Plano Provincial de Gestão Integral de Resíduos Urbanos de Entre Rios". Para tanto, define-se os objetivos e hipóteses a serem comprovadas, seguidamente apresenta-se a revisão do estado da arte na temática selecionada, o material bibliográfico, as entrevistas a informantes chave e a documentação relacionada com 0 objeto desta pesquisa. Posteriormente tenta-se verificar as hipóteses apresentadas para o que se descreve e analisa o desenho e a implementação da política de gestão integral de resíduos urbanos, e finalmente enunciam-se algumas conclusões.

\section{Introducción}

La temática ambiental surge en la década del 70 como consecuencia del acelerado crecimiento económico registrado en los países industrializados durante la etapa de posguerra. Frente a un panorama los estados comenzaron a incluir el aspecto ambiental dentro de sus agendas. En los años 80 se introduce un nuevo paradigma el concepto «desarrollo sustentable». Este concepto incorpora el tema de la equidad, tanto social como intergeneracional y plantea la necesaria articulación entre ambiente y desarrollo, colocando a la sustentabilidad ambiental en el tema central a ser considerado al momento de definir el modelo de desarrollo a seguir. En los años 90 en el marco de la negociación global sobre el desarrollo sustentable se instrumentan acuerdos y convenciones internacionales (Convención Marco sobre Diversidad Biológica, la Convención Marco sobre Cambio Climático, el protocolo de Kyoto entre otros), y además se crea el Fondo Mundial para el Ambiente Mundial manejado por el Banco Mundial. Por su parte Argentina comienza el nuevo milenio integrando los distintos foros internacionales sobre medio ambiente habiendo participado en la firma los distintos acuerdos y convenciones antes mencionados. También se registran avances en materia legislativa tales como las leyes de Bosques Nativos y General del Ambiente que establece la normativa para el logro de una gestión sustentable y adecuada del ambiente, la preservación y protección de diversidad biológica y la implementación del desarrollo sustentable. Además se registran algunos avances en legislaciones provinciales. № obstante lo cual estas acciones demandan continuidad y articulación entre los distintos niveles estatales y un manejo colaborativo de las distintas agencias implicadas. En los comienzos de la década del 2000 la política ambiental en Argentina estuvo bajo la órbita de la Secretaría de Ambiente y Desarrollo Sustentable (SAyDS), dependiente del Ministerio de Salud. En el año 2004 esta institución definió las «Bases de una agenda orientada a una Política Ambiental Sostenible para el Creci- 
miento y la Equidad» (SAyDS, 2004), partiendo de una descripción del estado de situación para proponer objetivos y líneas de acción que permitan materializar las políticas ambientales. A partir de la descripción diagnóstica en este documento se define y propone una denominada "agenda ambiental sustentable para el crecimiento» en la que se exponen políticas públicas en el marco de una visión estratégica y as herramientas consideradas necesarias para ello. En relación con la gestión de los Residuos Sólidos Urbanos releva la intensidad y extensión de la demanda originada en los niveles subnacional y local y propone dotar a la Secretaría respectiva de un plan — dotado de la flexibilidad necesaria - que permita registrar cuestiones de escala, de composición de los RSU, del soporte natural, de las condiciones socioeconómicas prevalentes de la población. Es en este marco que, en el año 2005, la SAyDS elabora la Estrategia Nacional para la Gestión Integral de Residuos Sólidos Urbanos (ENGIRSU) (SAyDS, 2005) que procura dar respuesta a los municipios, en tanto responsables directos de la gestión de RSU que no disponen de herramientas para enfrentar la problemática ambiental. Este documento establece los lineamientos conductores de la política ambiental, los objetivos, los propósitos, las líneas de acción y metas. Posteriormente fija para la implementación de las estrategias y los objetivos diferentes plazos, estipulando los de corto plazo para el año 2007, los de mediano plazo el año 2015 y los de largo plazo el año 2025. La implementación de esta política da origen al Plan Nacional de Gestión Integral de Residuos Sólidos Urbanos, que se asocia a un Proyecto del Banco Internacional de Reconstrucción y Fomento, «Gestión de la Contaminación», que le permitirá contar con asistencia financiera y oficiar a la vez de marco de referencia técnico. A 10 años de la formulación de esta estrategia y de la puesta en marcha de las diversas acciones líneas de acción la gestión de los RSU no exhibe cambios significativos. Por el contrario, estudios recientes señalan la continuidad y crecimiento de los «basu- rales a cielo abierto» y la ausencia de prácticas de «Separación y reciclaje de residuos» entre en sus aspectos centrales.

En lo que respecta al tratamiento de los residuos en la provincia de Entre Ríos no escapa, en líneas generales, a la situación planteada en párrafos anteriores descriptos en general al nivel nacional. Por este motivo la Secretaría de Ambiente de la provincia de Entre Ríos, a fin de abordar esta problemática, lleva adelante desde 2013 el «Plan Provincial de Gestión Integral de Residuos Sólidos Urbanos para la Provincia de Entre Ríos» financiado por Préstamo BID 1868/0C-AR. En una primera instancia se realizó el diagnóstico de la situación provincial donde se identificaron como principales problemas y con posterioridad se diseñó la política a implementar. En el presente trabajo se analiza la integralidad, coherencia y coordinación del diseño y se intenta mostrar si los avances en la implementación del Plan siguen los lineamientos plateados en los objetivos establecidos en la formulación del mismo.

\section{Objetivos e hipótesis}

En el presente trabajo se plantea analizar el diseño, formulación y la implementación en los municipios de la provincia de Entre Ríos del «Plan Provincial de Gestión Integral de Residuos Urbanos (GIRSU) de Entre Ríos». En una primera instancia, para este análisis, se establecen los objetivos definiendo como el principal la evaluación del desenvolvimiento de este Programa para lo cual se realiza un recorte, limitando el análisis geográfico al ámbito de la provincia de Entre Ríos. En este marco espacial determinado se aborda el proceso de diseño y formulación de esta política pública, con énfasis en la verificación del modo en que se analizan las cuestiones tales como: las dificultades de abordaje de políticas públicas centradas en lo sectorial porque las mismas demandan intervenciones multidimensionales; la relevancia en el planeamiento de 
políticas públicas de los conceptos de coordinación, coherencia e integralidad, etc. Estos aspectos operan como limitaciones o restricciones para el logro de los objetivos pretendidos en las políticas públicas.

Para alcanzar el objetivo general se proponen desarrollar objetivos específicos que intentan abordar los siguientes aspectos: 1)Describir y analizar la política GIRSU y evaluar su correspondencia con los criterios integralidad, coherencia y coordinación; 2) Verificar el grado de correspondencia de los objetivos formulados en orden nacional con los expuestos como tales en los niveles estatales provincial y local; 3) Evaluar la incidencia de la heterogeneidad de las capacidades institucionales locales en el grado de cumplimiento de las expectativas de los programas y proyectos; y 4) Verificar la sostenibilidad intertemporal de las políticas diseñadas.

De la revisión del estado del arte en la temática seleccionada, del material bibliográfico, de las entrevistas a informantes claves y la documentación relacionada con el objeto de esta investigación se intentan verificar las siguientes hipótesis: 1) La escasa integración vertical y/0 articulación de las distintas Agencias Ambientales relacionadas con la cuestión de los Residuos Sólidos Urbanos RSU; 2) La heterogeneidad de las situaciones locales — tanto en capacidad de gestión de los gobiernos como en las pautas culturales de la poblaciónque generalmente no son registradas en los Planes y Programas con que se implementan las políticas definidas a nivel nacional, conspira contra una implementación eficaz, reduce el nivel de logro de metas y objetivos y habilita reconfiguraciones subóptimas y 3) El financiamiento - tanto por sus características temporales como por su insuficiencia - contribuye a la escasa sostenibilidad en el tiempo de las políticas ambientales.

\section{Marco teórico}

La cuestión ambiental comprende una diversidad de aspectos de la vida social y económica de la población de un país. Configura además un horizonte en el que se perfilan los objetivos más genéricos que procura una sociedad y las políticas y acciones que se definen e implementan, en todos los aspectos del accionar público y privado, contribuyen en diversa medida a lograr — 0 a impedir — las metas existentes en el sendero que se dirige a hacia aquellos objetivos.

Es por ello que la problemática ambiental no es una cuestión más de la agenda gubernamental y social, sino que atraviesa el conjunto de las políticas públicas y las acciones gubernamentales, en todos los niveles estatales y también en las prácticas existentes en los agentes económicos y las conductas de la vida colectiva de los ciudadanos.

En la configuración de esta problemática, la Gestión Integral de los Residuos Sólidos Urbanos (en adelante GIRSU) tiene una relevancia especial. Es por ello que demanda de las políticas públicas ambientales el cumplimiento de pleno de criterios que aseguren la integración de la diversidad de actores involucrados y, a la par, la articulación y coordinación de múltiples acciones específicas concomitantes y concurrentes.

El abordaje de la temática del GIRSU demanda entonces el análisis de los diferentes enfoques de políticas públicas y de cómo se relacionan estos con la especificidad de la problemática abordada.

Vale entonces comenzar con las definiciones de las principales corrientes. Al respecto, Tamayo Sáez (1997:2) la define políticas públicas como «el conjunto de objetivos, decisiones y acciones que lleva a cabo un gobierno para solucionar los problemas que en un momento determinado los ciudadanos y el propio gobierno consideran prioritarios».

Ampliando el análisis señala que las políticas públicas constituyen un proceso 0 ciclo que comienza cuando un gobierno divisa la existencia de un problema y termina con la evaluación de los resultados de las políticas llevadas a cabo para 
resolverlo 0, al menos, mitigarlo. Proceso éste en el que identifica las siguientes fases: 1) Identificación y definición del problema, 2) formulación de las alternativas de solución, 3) adopción de una alternativa, 4).Implantación de la alternativa seleccionada y 5) evaluación de los resultados obtenidos.

Asimismo, debe tenerse en cuenta que, dado el carácter recurrente de esta problemática, el proceso tiene un desenvolvimiento cíclico y, en muchos casos, las políticas públicas no se desenvuelven estrictamente de acuerdo con la secuencia expuesta. Es de destacar entonces la importancia que adquieren aquí los conceptos de pertinencia, relevancia, integralidad y oportunidad, que resulta imprescindibles para disminuir los riesgos de fracaso de la implementación de normas, procedimientos y acciones específicas.

Otros autores, como Jaime, Dufour, Alessandro y Amaya (2013:77), coinciden con la periodización formulada, no obstante lo cual, a partir de estas etapas, realizan una desagregación más detallada agregando una etapa más - en rigor referida a la evaluación de procesos - que refiere a la actividad de ponderar los resultados de los monitoreos o la evaluación - que permite adoptar decisiones de continuidad, modificaciones o finalización de las actividades emprendidas.

Los autores previamente citados, en línea con los principales enfoques sobre el tema, afirman que las políticas públicas se cristalizan en programas y proyectos a los que se asignan recursos para ponerlos en práctica.

Estos proyectos constituyen la unidad más pequeña de desagregación para llevar adelante una acción y constituyen el punto de partida a partir del cual se integran los denominados Programas. De este modo los Programas agrupan aquellos proyectos cuyas metas y objetivos se orientan a resolver problemas de un área específica de políticas públicas. Por último, y en el mismo sentido, el conjunto de programas compone un determinado conjunto de políticas públicas. En este mismo orden Cohen y Franco (2005:109) definen las políticas públicas como agregados de programas.
A partir de esta conceptualización preliminar de las políticas públicas y de su contenido puede ahora abordarse el conjunto de aspectos específicos de aquellas políticas públicas que se orientan a afrontar la cuestión ambiental. A este respecto, se consideran los enfoques formulados por diversos autores en relación con los con los componentes y atributos específicos a las mismas. Por su parte Gligo (1997) distinguen dos tipos de políticas ambientales - explícitas e implícitas - donde la diferencia se establece a partir de los organismos que las generan. Así las políticas explícitas se formulan en los organismos centrales con competencia ambiental, mientras que las implícitas surgen en otros organismos o directamente en el poder central y son - casi siempre- decisiones relacionadas con el crecimiento económico. Como el horizonte de planeamiento de las políticas económicas (sectoriales, de empleo, de radicación industrial) suele ser el corto plazo, entran en conflicto con la dimensión ambiental del desarrollo sostenible, que demanda un enfoque de medio y largo plazo (Gligo, 1997:51).

Mientras que Gutierrez e Isuani (2013) introducen al debate una distinción relevante al considerar como una restricción importante para la implementación eficaz de una política ambiental al señalar que la principal limitación no radica en la ausencia de normas ambientales sino en la falta de implementación y cumplimiento de las normas existentes. Citan al respecto el hecho de que la nueva ley de Gestión de Aguas no fue reglamentada aún, o bien casos de normas que fueron promulgadas y reglamentadas pero no implementadas (v.g. glaciares) y, por último, los casos en que implementa con criterios que llevan a un cumplimiento «por debajo» de los estándares establecidos por la nueva norma nacional (v.g. bosques nativos).

Esta carencia que se traduce en un bajo nivel de implementación y falta de cumplimiento de la legislación ambiental involucra a los tres niveles de gobierno (nación, provincia y municipios). Además señalan que la normativa de carácter federal es 
—en muchos casos - reformulada por provincias y municipios que tienden a reducir la exigencia de los estándares nacionales 0 - simplemente - a no cumplirlos. Además llegan a no implementar la propia legislación, en la medida que estas normativas locales tienen vigencia meramente formal, dado que su origen se remonta al cumplimiento de compromisos con los niveles provincial y nacional.

En este sentido afirman:

Dada su dependencia normativa, financiera y/o política respecto de los gobiernos provinciales, los gobiernos municipales tienen escaso margen de maniobra más allá de las iniciativas provinciales o nacionales. Así las cosas, ¿cómo podría la política ambiental convertirse en una política de Estado, esto es, una política que cumple con sus objetivos declarados - tal como son formulados en la ley general del ambiente- a través de los sucesivos gobiernos? Una política de Estado requiere de «coherencia», lo cual supone a su vez la subordinación de las diversas políticas en juego a una concepción estratégica de parte del Estado. (Gutierrez e Isuani, 2013:325)

Vinculado a esta carencia, Isuani (2013:22) señala:

En ese sentido, no contar con una agencia ejecutiva dominante inhibe la coherencia y deja sin espacio material y simbólico para la orquestación de una visión integral sobre el ambiente. La ausencia una visión estratégica sobre el campo ambiental ha dejado sin chances cualquier expectativa de alcanzar cierta coherencia horizontal capaz de articular y dar convergencia a los objetivos de las diversas iniciativas impulsadas por los distintos actores estatales involucrados. Por su parte, la incongruencia manifiesta entre las aspiraciones contenidas en las normas generales y los dispositivos de gestión y los recursos dispuestos para ello, las han convertido en meros dibujos en el aire.

Esta incongruencia vertical y el modo en que los sucesivos proyectos políticos han abordado la cuestión ambiental en la provincia han hecho que "a esas normas que se caracterizan por su generalidad (...) se le oponen las reglas pragmáticas, que por supuesto no se publicitan: la «participación» se restringe a los grupos directamente reclutados en el aparato partidario articulado a ciertos líderes; el «avance hacia el desarrollo sustentable» encubre en realidad un aggiornamiento de las condiciones de acumulación de determinados sectores empresariales, a los que se les permite tácitamente una pésima gestión ambiental, el «énfasis en la educación ambiental y comunitaria» encubre producción de discursos diluyentes de las contradicciones; la «defensa del ambiente sano» disimula la deficiencia de los controles del aparato estatal, la permisividad prebendaría con los sectores empresariales, que siempre negocian utilizando la oposición «ambiente/trabajo" (Sarlingo, 2004:364 en Isuani, 2013:22).

Por su parte Lerda, Acquatella y Gómez (2003) destacan las limitaciones de las políticas públicas para operar eficazmente en ambientes de creciente complejidad política y económica, doméstica e internacional. Argumentando que las políticas sectoriales «no están debidamente integradas», por ejemplo hay algunas políticas macro de carácter emblemático que estarán en todo momento visiblemente integradas a la agenda pública, mientras que hay otras políticas sectoriales que, aun siendo importantes, solo reciben atención convencional. Las políticas sectoriales tampoco «guardan adecuada coherencia interna», y por ello entienden que las autoridades sectoriales fijan objetivos 0 metas mutuamente incompatibles, 0 en términos más generales, no guardan una interrelación lógicamente consistente. Por último consideran que las mismas «no se encuentran debidamente coordinadas», en relación con que los procesos, procedimientos e instrumentos de acción que son manejados de manera independiente y no sincronizada 0 , en términos más generales, sin la debida sensibilidad por las interdependencias e interacciones que existen entre políticas sectoriales (Lerda, Acquatella y Gómez, 2003:23). 
En referencia al concepto de integralidad Carlos Acuña advierte que problemas estratégicos a los que se enfrentan las políticas públicas, como la gestión integral de residuos, se caracterizan por una fuerte multicausalidad remitiendo este concepto a un conjunto de factores caracterizados por diversas propiedades y dinámicas, en los que se destacan los aspectos económicos, sociales, políticos, ideológico-culturales, organizacionales, etcétera, y por la profundidad que tiene esta problemática en los aspectos culturales y las raíces históricas de la comunidad donde se aplica la política. Cuando señala los aspectos relevantes del concepto de integralidad hace referencia a la noción de multicausalidad y considera que se deben tener en cuenta dos principios en su metodología de análisis y acción. El primero alude a la necesidad de tomar distancia de reduccionismos que «recortan» el accionar estatal sobre problemáticas complejas en líneas de acción paralelas, descoordinadas y hasta contradictorias en su atribución de monocausalidad al problema de agenda pública, encuentra su origen tanto en la lógica político-organizacional que otorga cuasi monopolios de acción temática a áreas ministeriales especializadas de manera discreta y angosta, como en la lógica de formación disciplinar de los expertos y profesionales que ocupan estos organismos. El segundo se liga a las acciones integrales que demandan coordinar aproximaciones multidisciplinarias, transversales, capaces de reconocer el cambiante mix entre la especificidad de una causa y su papel en el conjunto de determinantes intervinientes en una problemática dada (Acuña, 2010:9).

Otro aspecto relevante a tener en cuenta en el diseño de la política hace referencia a la coherencia. Este concepto adquiere relevancia cuando la integralidad del abordaje incluye otras dimensiones temáticas de modo que no impliquen una mera yuxtaposición sino que se imbriquen de modo tal de satisfacer los objetivos priorizando jerárquicamente más relevantes. A criterio de Carlos Bueno Suárez y José Luis Osuna Llaneza (2013) deben analizarse los aspectos internos a fin de evaluar el grado de compatibilidad de la estrategia en su conjunto, y el externo a fin de estudiar el grado de compatibilidad entre los objetivos perseguidos por la política diseñada y otros objetivos propuestos por otras actuaciones o incluso normativas de rango superior, igual o inferior a los que propone la política de intervención. Estas últimas, aun pudiendo ser ajenas a la política diseñada, pueden incidir positiva o negativamente en las posibilidades de ejecución y en el nivel de logro de de los resultados esperados.

Para ello, estos autores, plantean estudiar la política diseñada en dos ámbitos de análisis diferenciados, a saber: La coherencia Interna y la coherencia externa. Respecto de la coherencia interna. Requisito éste que se satisface con la existencia de una lógica concatenación entre los instrumentos y recursos de que se dispone, las acciones previstas en la intervención y los objetivos que se pretenden lograr. Muchas veces las imprecisiones en los objetivos o las presencias de políticas que plantean objetivos múltiples inducen a errores respecto de los propósitos sustantivos de la iniciativa y en algunos casos directamente no guardan relación con que se propusieron de forma explícita. En referencia a la coherencia externa, se analiza el grado de compatibilidad entre los objetivos perseguidos por la política diseñada y otros objetivos propuestos por otras actuaciones 0 incluso normativas de rango superior, igual o inferior a los que propone la política de intervención.

En referencia al concepto de coherencia Martínez Nogueira (2010) se refiere a los objetivos buscados - por consiguiente, a los resultados e impactos de las políticas - y a la capacidad para que éstos sean sinérgicos, acumulables, no contradictorios 0 mutuamente neutralizadores. A criterio de este autor la coherencia es previa a la coordinación, pues se dirige a los fines y orientaciones de las acciones. Es una cualidad «vertical» que se manifiesta en la articulación lógica entre la visión de país, la estrategia, los objetivos y los instrumentos de política. Mientras que la coordinación tiene por objeto la consistencia en el plano «horizontal», 
interno al universo de los medios que constituyen las políticas. La coherencia y la coordinación se localizan tanto en el plano político (gobernabilidad, actores, liderazgos, capacidades, etc.) como en lo técnico (movilización de conocimientos, existencia de dispositivos analíticos, sistemas y procedimientos para la anticipación y el cálculo para la evaluación de alternativas y para la acumulación de aprendizajes, etc.). Los problemas de coherencia y coordinación se originan en distintos momentos: la coherencia se refiere en mayor medida a la identificación de los problemas a cuya resolución se dirigen las políticas, a los conflictos y tensiones a que da lugar su conceptualización y a los criterios que prevalecen en la selección de los medios. Es en la ejecución y, por lo tanto, en la coordinación, es donde se manifiestan prioritariamente las restricciones y defectos de los diseños adoptados. Por su parte, Repetto identifica tres planos en los que puede ser necesaria la coordinación: El plano horizontal intersectorial, el vertical interjurisdiccional y el vínculo con actores no estatales. Respecto de la coordinación intersectorial hace referencia a los distintos sectores estatales, el plano interjurisdiccional evalúa qué mecanismos existen para coordinar la actividad entre autoridades de distinta jurisdicción y el vínculo con actores no estatales pone el acento en la necesidad de tener una gestión coordinada entre el estado y actores de la sociedad civil (Repetto, 2005 en Repetto y Fernández, 2012).
Acuña considera que el otro factor relevante que tiene que tener una política ambiental es la sustentabilidad intertemporal, ello implica el eficiente uso de recursos escasos y consistencia en la visión sobre la sociedad a la que se tiende, esto es, sobre las prioridades y el orden temporal que enhebran un accionar estratégico de mediano-largo plazo. Este autor considera la necesidad de contar con una coordinación de programas y políticas públicas, que resulte en un accionar coherente, integral y sostenido en el tiempo sobre los problemas estructurales que minan la equidad y el desarrollo en nuestras sociedades (Acuña, 2010:9).

El análisis de la política GIRSU, por tratarse de uno de los principales problemas ambientales en la provincia de Entre Ríos, se caracterizan por una fuerte multicausalidad ello coloca su foco en el análisis de la integralidad de la política, la evaluación de la coherencia (interna y externa), y por último consideran si las mismas coordinadas. También resulta relevante evaluar si esta política ambiental cuenta con normas de regulación en los distintos niveles de gobierno y si se están cumpliendo e implementando. Además se pretende verificar si la normativa de carácter federal mantiene sus estándares en la provincia y los municipios, vale decir si no tienden a reducir la exigencia 0 a no cumplirlas. Se considera que para que una política pública resulte se eficiente y eficaz se debe contar con un accionar coherente, integral, coordinado y sostenible en el tiempo. 


\section{Del diagnóstico y el diseño de las políticas de gestión de RSU a la implementación de las acciones. Criterios de eficacia y relaciones interestatales}

\subsection{Descripción de los actores}

involucrados en la gestión integral de residuos sólidos urbanos

En el ámbito geográfico e institucional que comprende tanto las actividades de generación de RSU como la gestión de los mismos interviene una multiplicidad de actores, públicos — de los distintos niveles estatales-, privados, del tercer sector e, incluso, organismos multilaterales de financiamiento.

En el nivel nacional, el responsable institucional máximo en relación con todos los temas ambientales es el Ministerio de Ambiente y Desarrollo Sustentable (MAyDS). Un aspecto de esa temática, la política GIRSU, está a cargo de la Secretaría de Coordinación Interjurisdiccional que cuenta, a su vez, con un organismo específico que tiene a cargo la coordinación de Gestión Integral de Residuos Sólidos Urbanos.

En relación con este nivel institucional, el acuerdo de préstamo celebrado por el MAyDS con el Banco Interamericano de Desarrollo (BID) para la implementación del «Programa de Gestión Integral de Residuos Sólidos Urbanos en Municipios Turísticos. Préstamo 1868/0C-AR», introdujo a este organismo en el proceso de diseño, formulación y gestión de las políticas específicas como un actor calificado.

En el nivel subnacional, en este caso la provincia de Entre Ríos, las políticas ambientales están en la órbita de la Secretaría de Ambiente que, interviene activamente en guiar las actividades y políticas en materia de gestión de residuos.

En el terreno estatal, por último, se encuentran los gobiernos locales que son los principales responsables de materializar buena parte de las actividades que surgen de las definiciones políticas en términos de gestión de residuos.
En el ámbito del tercer sector, fundamentalmente en el área geográfica de Entre Ríos, se encuentran vinculadas con la temática de los RSU algunas pequeñas organizaciones tales como ONG locales o los denominados EcoClubes, como así también organizaciones informales provenientes de estudiantes secundarios y primarios.

Mientras que las entidades de carácter privado aparecen con diversos niveles de protagonismo en el proceso de recuperación, acopio y comercialización de materiales reciclables. En este espacio conviven pequeñas empresas con diverso grado de formalidad, desde acopiadores/comercializadores con desarrollo regional hasta cooperativas que trabajan en plantas de separación y recolectores informales.

\subsection{Análisis del cumplimiento de los objetivos (en el marco de las limitaciones y restricciones)}

4.2.1. Descripción y análisis la política GIRSU. Análisis y evaluación de los criterios integralidad, coherencia y coordinación

Para el diseño y la implementación de las políticas GIRSU se deben analizar un variado conjunto de entidades con distintos tipos de roles y competencias, directas o indirectas, asociadas con la gestión y control de los residuos. Esto genera en la práctica una superposición parcial de roles, tanto en las competencias normativas como en las funciones de vigilancia y control en los distintos niveles de gobierno. Es por ello que los teóricos destacan las limitaciones de las políticas públicas, y en particular la GIRSU, para operar eficazmente en ambientes de creciente complejidad política, social, institucional y económica, argumentando que las políticas sectoriales no están debidamente integradas, tampoco guardan adecuada coherencia y no se encuentran debidamente coordinadas. Ello motiva el análisis de la importancia que se les dio a cada uno estos criterios en la formulación e implementación del Plan Provincial, a continuación de desarrollan cada uno de ellos. 
Para estudiar el criterio de integralidad se analizó la formulación del Plan Provincial evaluando la documentación referida al diseño y la formulación, sumadas a las propuestas de intervención que fuera elaborada y, luego, aprobada por la Secretaría.

Se advierte allí, en una primera aproximación, que se cuenta con un detallado diagnóstico sobre las problemáticas sociales, económicos, ambientales, políticas e institucionales que afectan a la gestión de residuos en los municipios y que si bien se realizó un abordaje de la problemática planteada de manera multicausal la formulación de los proyectos se centralizó solamente en la materialización física de las iniciativas (incorporación de camiones recolectores, adquisición de Planta de Separación de Residuos e instalación del sitio de disposición final). Otro aspecto a destacar es que a Io largo de la formulación se observa poca relevancia de los aspectos sociales, educacionales, comunicacionales, organizativos e institucionales lo que redunda en un escaso desarrollo de estos temas. Este sesgo o directamente la omisión del análisis de dimensiones concurrentes en la generación de la problemática, muestra una falta de integralidad que orienta el análisis y lo reduce a los aspectos relacionados con los aspectos materiales y financieros de la inversión, lo que conlleva a diseños subóptimos y de eficacia reducida.

Para evaluar el criterio de coherencia Carlos Bueno Suárez y José Luis Osuna Llaneza (2013) consideran que deben analizarse los aspectos internos a fin de evaluar el grado de compatibilidad de la estrategia en su conjunto, y el externo a fin de estudiar el grado de compatibilidad entre los objetivos perseguidos por la política diseñada y otros objetivos propuestos por otras actuaciones 0 incluso normativas de rango superior, igual 0 inferior a los que propone la política de intervención. Estas últimas, aun pudiendo ser ajenas a la política diseñada, pueden incidir positiva o negativamente en las posibilidades de ejecución y en el nivel de logro de de los resultados esperados.
Para ello, estos autores, plantean estudiar la política diseñada en dos ámbitos de análisis diferenciados, a saber: La coherencia interna y externa.

En relación con el objeto de este trabajo se procedió a analizar la coherencia interna a partir de los cinco objetivos propuestos en su formulación. Para ello se evaluó la lógica concatenación entre los instrumentos y recursos de que se dispone, las acciones previstas en la intervención y los objetivos que se pretenden lograr, los mismos se detallan a continuación:

- «Lograr la implementación de la Gestión Integral en la provincia» ( $1^{\circ}$ OBJETIV0)

- «Lograr minimización de los RSU, y maximización de su valorización mediante recuperación y reciclado» ( $2^{\circ}$ OBJETIVO);

- «Lograr la clausura de los Basurales y microbasurales a Cielo Abierto» ( $3^{\circ}$ OBJETIVO);

- «Recopilación, procesamiento y difusión de la información relativa a la GIRSU» (4 OBJETIVO); y

- «Lograr una adecuada comunicación y una activa participación ciudadana en todos los aspectos relacionados con la GIRSU» ( $5^{\circ}$ OBJETIVO).

En ellos se puede observar que el objetivo 1 implica la puesta en marcha del GIRSU en todo el territorio provincial. Para ello es preciso traer a colación la definición que se hace el art. 5 de la Ley provincial 10311/2014 —Gestión Integral de los Residuos Sólidos Urbanos de la Provinciasobre el concepto de gestión de residuos, entendiéndose como:

el conjunto de acciones interdependientes y complementarias que se efectúan para dar a los residuos sólidos urbanos un destino adecuado, de una manera ambientalmente sustentable, técnica y económicamente factible y socialmente aceptable, con el objeto de preservar la salud de la población, los recursos naturales y el ambiente. La gestión integral de residuos sólidos urbanos comprende las siguientes etapas: generación, disposición inicial, recolección, transporte, transferencia, tratamiento, valorización y disposición final. (Ley provincial 10311/2014, Art. 5) 
Al revisar este concepto se puede afirmar que el resto de los objetivos (del segundo al quinto) planteados en el documento se consideran necesarios para lograr el primero, siendo estos concordantes, complementarios y necesarios para alcanzar el objetivo principal. Este aspecto hace a la coherencia interna de la política a implementar, pero además es preciso verificar como se concatenan los instrumentos y las acciones previstas en la intervención para materializar los objetivos.

Para cada objetivo se plantean diferentes líneas de acción y actividades que se analizan a continuación para ver si satisfacen el criterio de coherencia interna.

En relación con el Objetivo $\mathrm{N}^{0} 1$, se propone llevar adelante cuatro líneas de acción; la primera de ellas plantea dotar de apoyo técnico a los municipios, la segunda es la asistencia económica y financiera que permita generar mecanismos que faciliten el acceso a fondos a los municipios, en tercer lugar se propone contribuir a formular e implementar una tarifa única de equilibrio entre los municipios y por último, se prevé el fortalecimiento institucional de las áreas responsables en cada municipio. Las líneas de acción contribuyen a lograr la implementación de este objetivo pero no parecen ser suficientes para que efectivamente se materialicen en los Municipios. Conspira contra esta posibilidad la autonomía de las jurisdicciones municipales y la inexistencia de acuerdos institucionales que resuelvan esa dificultada, junto con la definición poco clara y desagregada de los instrumentos y procedimientos con que se cuenta en los niveles nacional y provincial para financiar las actividades a realizar.

En cuanto al Objetivo $\mathrm{N}^{0} 2$, se formulan tres líneas de acción, a saber: la primera se sugiere la implementación de actividades de Educación, Comunicación y Participación Ciudadana, la segunda línea de acción hace hincapié en el Fomento a la reducción en origen y la valorización de los RSU a nivel provincial, la última línea de acción se propone colaborar con la sanción de una Ley de Envases y una Ley de Residuos de Aparatos Eléctricos (RAE). Estas líneas de acción contribuyen a lograr la primer parte del objetivo es decir a «lograr minimización de los RSU» pero no parecen ser suficientes para alcanzar los objetivos mencionados en la segunda parte «y maximización de su valorización mediante recuperación y reciclado» puesto que no hay una acción destinada por ejemplo al desarrollo del mercado.

En relación con el $3^{\text {er }}$ objetivo, se plantean tres líneas de acción, a saber: brindar apoyo técnico necesarios a los municipios para la realización diagnósticos ambientales, en segundo lugar se formula una línea de acción destinada a lograr la asistencia económica y financiera, mediante la facilitación del acceso a fondos para los municipios y por último se enuncia una línea de acción referida a la Adecuación de la Legislación que plantea promover el establecimiento de sistemas de recomposición del ambiente como parte de los regímenes sancionatorios de la normativa que se dicte respecto. En cuanto al apoyo técnico y a las actividades planteadas para esta línea de acción son concordantes y guardan un cierto grado de coherencia con el objetivo planteado. No se aprecia lo mismo con las otras líneas de acción dado que no hay previsiones ni información sobre la viabilidad de la asistencia económica y financiera requerida y tampoco se enuncian mecanismos posibles que permitan una adecuación legislativa que involucre institucionalmente a los Municipios, habida cuenta la autonomía de los mismos.

En relación con el $4^{\circ}$ objetivo, se plantea generar información confiable y apropiada que pueda estar disponible para el análisis y la evaluación específica de cada una de las actividades que impliquen las mejoras pretendidas y, a la vez, que contribuyan a la formulación de las políticas de Estado en materia de GIRSU. Las líneas de acción y actividades son compatibles con el objetivo, pero al igual a lo descripto en el punto anterior se trata de una exposición de motivos sin mención ni desarrollo de los recursos que se dispondrán al efecto ni de los instrumentos a utilizar y las acciones que se prevén ejecutar para estos efectos.

Por último, en relación con el objetivo $5^{\circ}$, el Plan prevé la realización de campañas de comunicación 
de las diferentes acciones que se lleven a cabo, y el establecimiento de una efectiva concientización social respecto de la trascendencia del cambio que se busca provocar.

Este objetivo se superpone con la línea de acción Educación, Comunicación y Participación Ciudadana planteada para satisfacer el Segundo objetivo, en lo atinente a comunicación y participación ciudadana, por lo cual caben los comentarios realizados precedentemente.

La coherencia externa, por su parte, es analizada poniendo el acento en el grado de compatibilidad entre los objetivos perseguidos por la política diseñada y otros objetivos propuestos por otras actuaciones 0 incluso normativas de rango superior, igual 0 inferior a los que propone la política de intervención. También corresponde considerar las acciones, actuales o previstas, de otros organismos de jerarquía similar cuyas políticas impactan en el ámbito territorial, institucional u organizativo en que se materializará la intervención. Este análisis comprende acciones actuales y previstas de los siguientes ámbitos:

- Ios de legislación y regulación, que, por su carácter imperativo, deben ser tenidos en cuenta por el diseño de la intervención objeto de evaluación;

- los de intervención de otras áreas de competencia en las que se comparten objetivos, población objetivo u otros elementos que debieran ser analizados con objeto de detectar las oportunidades sinérgicas o bien los eventuales conflictos entre áreas, objetivos o instrumentos.

A modo de resumen se puede apreciar que hay cierta congruencia entre los contenidos diseñados para la política GIRSU y los objetivos definidos en otras jurisdicciones provinciales. Pero no se puede decir lo mismo respecto del diseño de las políticas a implementarse en las jurisdicciones locales donde hay incertidumbre sobre su aplicación debido a la autonomía jurídica de las localidades y de los tiempos que le lleve a materializar dicha política.

En relación con el criterio de coordinación de las políticas públicas, este aspecto se aborda metodológicamente desde la óptica propuesta por Repetto, que identifica tres planos en los que se manifiesta la coordinación, ello son: el plano horizontal intersectorial, el plano vertical interjurisdiccional y el vínculo del Estado con actores no estatales.

Del relevamiento realizado desde el punto de vista horizontal intersectorial la Secretaria de Ambiente lleva adelante un gestión de la política ambiental transversal a las distintas jurisdicciones administrativas que conforman el gobierno provincial, desde el punto de vista de las organizaciones en los distintos niveles de gobierno no se observa duplicación de unidades administrativas cumpliendo la misma función ni tampoco se observa duplicidad de esfuerzos dentro de un mismo sector. Si se analiza el ámbito operativo de las políticas se visualiza cierto grado de interacción y sinergia con otros organismos provinciales aunque es preciso aclarar que es muy incipiente.

Para considerar la coordinación entre distintos niveles de gobierno — plano vertical interjurisdiccional- se observa una importante interacción en la coordinación de políticas entre Ministerio de Ambiente y Desarrollo Social (MAyDS) y La Provincia. La misma se ve reflejada en los convenios firmados entre estas jurisdicciones y que se repercute en la implementación de diferentes proyectos. Otro elemento que muestra la interacción existente es la conformación de COFEMA, institución que lleva adelante la «coordinación interjurisdiccional» de las políticas de gestión de residuos definidas a nivel nacional.

En la mirada de esta política hacia las escalas territoriales inferiores, provincia-municipio, la Secretaria de Ambiente provincial lleva adelante la coordinación del política GIRSU con los municipios facultada por la Ley Provincial GIRSU. Ello lo complementa con la creación del Consejo Ambiental Provincial (COPROAM) que lleva adelante la coordinación intermunicipal de la política GIRSU, aunque de manera incipiente. Se observan algunos avances en la organización de distintas zonas de la provincia 
impulsando la regionalización de las actividades GIRSU. Los informantes claves consideran que existe una buena coordinación entre los distintos niveles jurisdiccionales pudiéndose mejorar aspectos relacionados con las comunicaciones, sobretodo en la relación provincia-municipio.

Con los actores no estatales no se aprecia una metodología definida por parte de la Secretaría de Ambiente provincial respecto del tratamiento e implementación de la política GIRSU ni tampoco un espacio formal donde materializar decisiones políticas peri si hay esfuerzos aislados si hay algunos avances en el ámbito municipal.

\subsubsection{Análisis de correspondencia de los obje- tivos formulados en el nivel nacional con los que surgen de los Planes, Programas o Proyectos formulados en el marco de la política GIRSU en los niveles estatales subnacionales}

En este apartado se analiza y se contrasta si los objetivos planteados en la normativa federal fueron respetados y contenidos en la propuesta provincial y municipal. Se puede señalar que de la información relevada la normativa definida a nivel provincial (Ley 10311) está alineada con las normas y estrategias definidas a nivel nacional (Ley 25916) donde se aprecia una cierta congruencia con las pautas definidas por el gobierno nacional. Además se puede considerar que mantienen la exigencia de los estándares determinados en esta normativa. El costado negativo en este punto es la demora en la reglamentación de la normativa provincial (en el Art. $35^{\circ}$ de dicha norma establece un plazo de 6 meses para reglamentar esta ley que fue promulgada en 2014), y hasta el momento no se ha dado cumplimiento por lo que no resulta posible materializar la implementación en campo de la norma y tampoco se ha constituido el fondo que permite financiar las actividades.

Del relevamiento realizado a nivel municipal existe un bajísimo porcentaje de municipios que han adaptado su normativa a las definidas a nivel nacional y provincial, ya que los municipios que no disponen de normativa GIRSU 0 disponen de normativa asilada sobre este tema representan un $74 \%$ de la muestra. Ello implica falta de cumplimiento 0 de cumplimiento parcial a los objetivos fijados en los niveles superiores.

De los municipios que si poseen normativa GIRSU se analizó la legislación y se puede apreciar que tiene coherencia y congruencia con las normas definidas a nivel nacional y provincial. Pero se observa que hay un bajo nivel de implementación de la normativa local en acciones concretas.

\subsubsection{Análisis de la incidencia de la hetero- geneidad de las capacidades institucionales locales en el grado de cumplimiento de los obje- tivos y expectativa de los programas y proyectos}

Para evaluar la heterogeneidad de las capacidades institucionales y el grado de cumplimiento del programa implementado a nivel provincial y local se analizaron y estudiaron tres aspectos relevantes a saber: 1) Institucionales. En este punto se evalúa la capacidad institucional de los organismos provinciales y locales encargados de implementar y llevar adelante los objetivos definidos en la normativa, y también los avances realizados hasta el momento; 2) Ambientales. En este caso para identificar la existencia de capacidades diferenciales de los municipios para brindar el servicio de GIRSU. Se analizan aquí las características del servicio brindado en los distintos municipios teniendo en cuenta las diferentes etapas: barrido, recolección, separación y disposición final, y luego se compraran los avances producidos antes y después de la sanción de la ley GIRSU; y 3) Sociales. Que comprende las formas en que se abordan la multiplicidad de problemáticas existentes en los grupos vinculados a la recuperación informal de residuos, la existencia de programas y políticas específicas y las previsiones existentes para el tratamiento de áreas sociales y geográficas marginales.

\section{Aspectos institucionales}

Para analizar la capacidad institucional se evaluaron las áreas afectadas o dedicadas a la GIRSU. Para ello se tuvo en cuenta tanto en nivel provincial como 
local la existencia de áreas exclusivas destinadas a gestionar la política. También se evalúo los recursos humanos dedicados a esta actividad, en el caso provincial se tuvo en cuenta la calidad del personal afectado a las tareas y en el caso municipal la cantidad de personal afectada a esta actividad en relación con el total de la población beneficiaria

Del relevamiento realizado en el nivel provincial se señala como principal fortaleza la capacidad de gestión del Organismo encargado de llevar a delante la política GIRSU fundada en la organización administrativa dividida en dos regiones geográficas, esto le permite abordar el trabajo con mayor celeridad y cercanía a las cuestiones territoriales. La debilidades se puntualizan en la escasa cantidad y calificación del personal en el área de residuos ya que se debe abordar esta problemática con solo 5 personas todo el territorio provincial (78 municipios y 180 juntas de Gobierno) y además de la falta de personal especializado en la temática (solo cuenta con un solo profesional en la temática). Otro aspecto importante de marcar es la falta de sistematización de la información que no permite construir indicadores para monitorear la política GIRSU llevada adelante. Las cuestiones antes mencionadas se traducen en una baja capacidad de implementación de la política y por ende perdida de eficiencia y eficacia de la política diseñada.

A nivel municipal se evaluaron las áreas dedicadas a la GIRSU para visualizar el grado de autonomía de los municipios para llevar a cabo la gestión de residuos. De la información relevada se desprende que solo el $13 \%$ de los municipios cuentan con una como dependencia con el rango de Secretaría de Ambiente y el 87 \% restante las actividades GIRSU se realizan a través de la Secretarias de Obras Públicas. De esta información surgen dos cuestiones relevantes, la primera, son pocos los Municipios que cuentan con organismos con el rango de Secretaría de Ambiente, disponer con instituciones de esta jerarquía da la posibilidad de manejar presupuesto, poder de decisión, etc., ello impacta directamente en la escasa autonomía del resto de los municipios para manejar la política GIRSU; la segunda cuestión muestra que la mayoría de los Municipios gestionan la GIRSU a través de las Secretarías de Obras Públicas dejando en evidencia la poca importancia relativa otorgada a los aspectos ambientales y en particular a la GIRSU. En la ilustración se puede apreciar que hay aproximadamente un $45 \%$ de las Municipios que disponen de áreas destinadas a cuestiones ambientales de las cuales solo un $23 \%$ tienen un sector que se dedica específicamente a la GIRSU. El $55 \%$ de los Municipios restantes realizan las actividades de barrido, limpieza, recolección y disposición final dentro de la Secretarias de Obras Públicas sin depender de un área ambiental que coordine y gestione estas actividades lo que dificulta llevar adelante políticas coordinadas.

Ilustración 1. Existencia de áreas específicas GIRSU

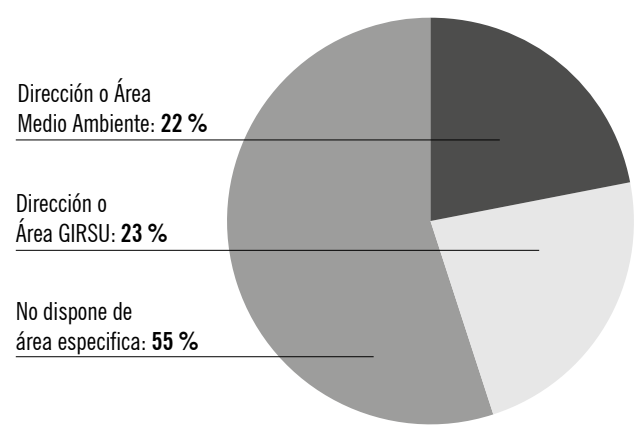

Fuente: Elaboración propia con datos proporcionados por el Plan Provincial (Secretaria de Ambiente, 2013) y Municipios

Nota: Se relevaron un total de 33 municipios de la Provincia de Entre Ríos: 1 Paraná, 2 Concordia, 3 Gualeguaychú, 4 Concepción Del Uruguay, 5 Gualeguay, 6 Chajarí, 7 Villaguay, 8 Victoria, 9 La Paz, 10 Colon, 11 Nogoyá, 12 Crespo, 13 Diamante, 14 San José, 15 Federal, 16 Santa Elena, 17 Federación, 18 Rosario Del Tala, 19 San Salvador, 20 San José De Feliciano, 21 Villa Elisa, 22 Basavilbaso, 23 Viale, 24 San Benito, 25 General Ramírez, 26 Villa del Rosario, 27 Ibicuy, 28 Oro Verde, 29 Villa Paranacito, 30 Ubajay, 31 General Campos, 32 Colonia Avellaneda, 33 Ceibas 
Bach / Articulación interestatal en la gestión de residuos...

También se tuvo en cuenta en el análisis la cantidad de personal afectado a esta actividad por representar el costo más importante de la GIRSU. Para hacer el estudio se utilizaron diversos indicadores. A modo de ejemplo, si se toma la relación entre cantidad de recursos humanos destinados la GIRSU y la cantidad de población, se aprecia una gran heterogeneidad en los distintos municipios, por caso, los más pequeños utilizan casi 4 empleados cada 1000 habitantes y, en los más grandes, a medida que aumenta la población de la localidad, la relación cantidad de empleados/población se reduce a casi la mitad, lo que impacta necesariamente en el nivel de servicios de la GIRSU (ver la siguiente llustración.).

Ilustración 2. Indicadores de personal agrupado por tamaño de municipios. Año 2014

Cantidad de empleado GIRSU

cada 1000 habitantes

Cantidad de empleados

Municipales cada 1000

habitantes

Cantidad de empleados

Municipales cada 1000

habitantes
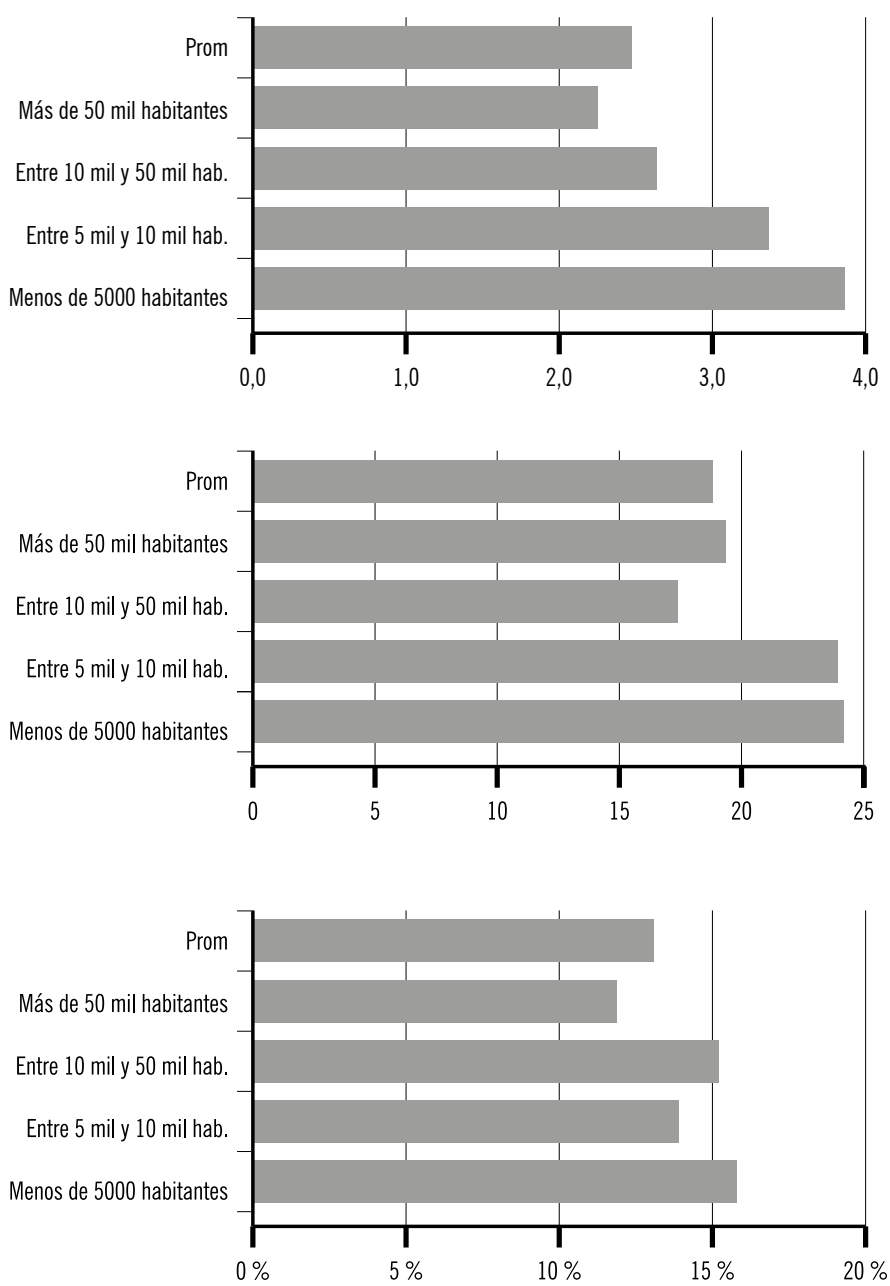
Para completar el análisis se toma como indicador la importancia que le asignan los municipios a cada una de las etapas de la GIRSU y para ello se tiene en cuenta la cantidad de personal destinado a cada una de estas etapas. Se observa aquí también que la proporción depende del tamaño del Municipio. A modo de ejemplo, en localidades intermedias (entre 5 y 10 mil habitantes y entre 10 mil y 50 mil habitantes) la cantidad de recursos humanos destinados a las tareas de «separación» están en torno al $13-14 \%$ del total respectivamente, muy por encima de las localidades de más de 50 mil habitantes que solo le destinan el $2 \%$ los recursos humanos y los municipios de menos de 5 mil habitantes el $9 \%$. Esto refleja nuevamente la heterogeneidad en el nivel de servicios brindados en cada municipio que para el caso las actividades de separación no se condicen con los volúmenes de residuos y eso también impacta en el nivel de servicios (ver la siguiente llustración)

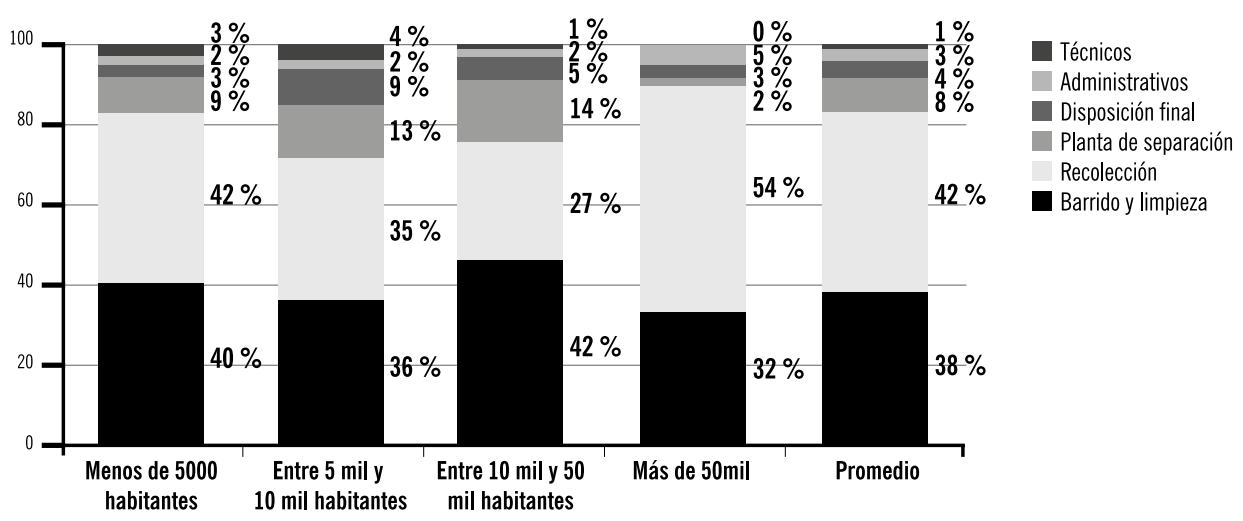

Fuente: Elaboración propia en base a datos proporcionados en el Plan Provincial y relevamientos a Municipios (Secretaría de Ambiente, 2013)

\section{Aspectos ambientales}

Para evaluar cómo se gestionan los residuos en La Provincia luego de la sanción de la Ley GIRSU se analiza los avances después de la implementación de la norma. Para ello se tuvieron en cuenta las opiniones de informantes claves (funcionarios, provinciales, municipales y representantes de la empresa consultora encargada de formular el plan) que expusieron su visión respecto del funcionamiento de la GIRSU en los municipios. Desde la empresa consultora destaca como prin- cipales fortalezas en el manejo de la GIRSU a los recursos humanos municipales disponibles para la GIRSU y la cobertura de los servicios de higiene urbana. Las principales debilidades están dadas en la baja importancia que le dan los municipios a la separación en origen de los residuos domiciliarios y el servicio de recolección diferenciada, la poca disponibilidad de terrenos adecuados y libres para la implantación de un Relleno Sanitario y la existencia de basurales a cielo abierto. Además consideran que los Municipios entrerrianos son 
heterogéneos en cuanto a niveles de desarrollo de la GIRSU, encontrándose muchos municipios donde se llevan a cabo las etapas de una GIRSU de forma adecuada y completa y otros municipios donde solo se realiza la recolección y la disposición final de los residuos en un basural a cielo abierto sin ningún tipo de tratamiento. De acuerdo con este factor las realidades son muy distintas entre muchos de los municipios que formaron parte del Plan.

En el mismo sentido funcionarios municipales opinan que «Hay municipios puntuales que han trabajado mucho en las etapas iníciales de gestión de RSU y están preparados para implementar un relleno sanitario, pero en termino generales los municipios tienen una baja capacidad técnica para gestionar correctamente los RSU. La mayoría tiene un tramo importante que recorrer, por ejemplo tienen que consolidar sus direcciones de ambiente, tener personal abocado exclusivamente a la GIRSU, etc. Igualmente se observa una gran cantidad de localidades que están iniciando el proceso de aplicación de la política pero ello se materializa a mediano largo plazo»

Desde los funcionarios provinciales afirman respecto de la implementación del plan consideran que «se observan avances dispares en la aplicación de esta política, muchos lo han hecho con más voluntad que capacidad por ejemplo hay lugares que tienen un mayor avance y han logrado implementar su planta de separación, o de transferencia, o plantas de residuos especiales. Los avances señalados fueron realizados al margen de la implementación del plan, pero si se destaca del plan la solución que se propone a la última etapa de la GIRSU». También rescatan que el plan ayuda a la incentivación ya que muchos municipios han ido implementando proyectos vinculados a las actividades de separación, la implementación de promotores ambientales todo ello en perspectiva de la posibilidad que exista un sitio de disposición final.

Se ha observado que luego de la formulación han existido pocos avances en la implementación de la política motivado por la falta de inversión, provocado básicamente por la falta de financiamiento de las inversiones presentadas en los proyectos. Tampoco se aprecia progresos en los aspectos institucionales antes mencionados.

De la descripción realizada se puede verificar la existencia de capacidades heterogéneas en los distintos municipios respecto de la disponibilidad de los recursos humanos, materiales y a las capacidades institucionales existentes. Se han podido encontrar ciertos rasgos característicos marcados básicamente por la diferencia de tamaños de los mismos. La política diseñada ha intentado tener en cuenta estas diferencias en cuanto a los aspectos legales, ambientales, económicos y técnicos, pero desde el punto de vista institucional no lo han logrado plasmar ni diseñar los instrumentos adecuados para llevar a cabo su implementación.

\section{Aspectos sociales}

Por último se evalúan los aspectos sociales en donde se pudo comprobar con los datos proporcionados por el plan que el $75 \%$ de los municipios cuentan con recuperadores informales en sus localidades según datos aportados en el Plan Provincial. Actualmente en las localidades de Paraná y Concordia se llevan adelante programas que han tenido un gran avance hacia la formalización de las actividades de los recuperadores a través de cooperativas conformadas por los mismos, actividades de capacitación, dotación de recursos materiales y accesibilidad al crédito. En las otras localidades no se ha podido cotejar el mismo progreso en este tipo de programas. Por otra parte se señala que en los proyectos ejecutivos (PE) diseñados en el marco del Plan Provincial y que han sido presentados a la Secretaría de Ambiente de la Nación (Nodo Paraná, Nodo Concordia, Nodo Santa Elena y San José) incluyen un «Plan De Gestión Ambiental y Social del PE» para cada uno de ellos. En los mismos se desagregan las estrategias y programas respectos a los aspectos ambientales pero tiene un bajo nivel de desarrollo en los aspectos sociales lo que dificulta su implementación posterior. 
4.2.4. Análisis de la sostenibilidad intertemporal de la implementación de acciones y actividades que surgen de las políticas diseñadas

La posible sostenibilidad intertemporal de la política se manifiesta en diversas dimensiones, por un lado en lo económico y financiero, para lo cual se explora y analiza los principales recursos generados por la gestión de los RSU. En el mismo sentido se analiza el aspecto institucional y para ello se estudia el marco legal-institucional junto con la dotación y características de los recursos humanos y tecnológicos actuales y previstos - en los distintos municipios. Ambas temáticas se abordan de manera general profundizándose en los proyectos llevados adelante en el Plan Provincial.

\section{Dimensión económica}

Del relevamiento realizado surge que la GIRSU tiene como fuente principal de sostenimiento financiero la posibilidad de cobro de tasas municipales y también, aunque en menor medida, los ingresos generados de la comercialización del material recuperado. Los recursos provenientes de fuentes tributarias ${ }^{1}$ cubren en la actualidad parcialmente la gestión de residuos, aproximadamente un $28 \%$ del costos, tal como se puede ver en la siguiente llustración

Ilustración 4. Ingresos Tasa General Inmobiliaria versus Costo GIRSU. Municipios seleccionados. Año 2013

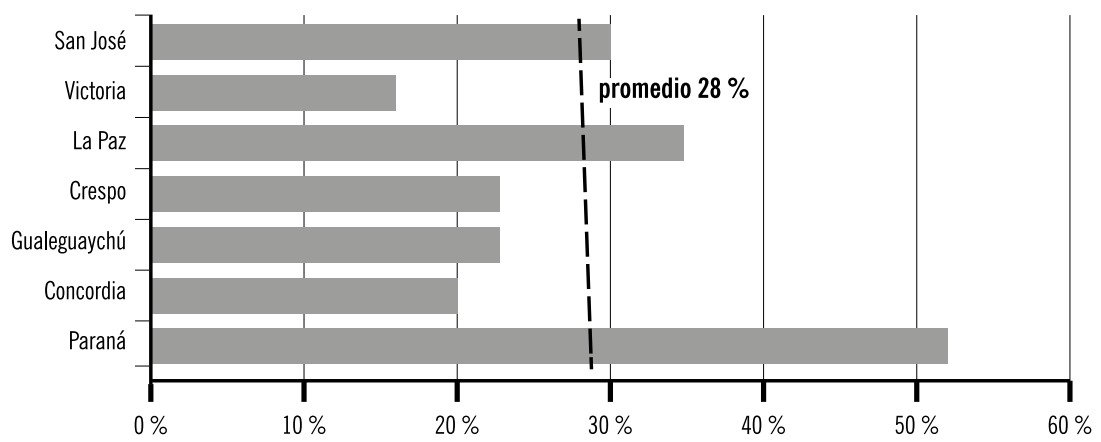

Fuente: Elaboración propia en base a datos obtenidos de Planilla GIRSU Secretaría de Ambiente de la Nación elaborada por cada municipio

En el plan se propone implementar el cobro de una tasa específica y del relevamiento realizado surge que esta tampoco lograría abarcar la totalidad de los costos del servicio. En la tabla se puede apreciar que la cobertura de la tasa cubriría entre un $13 \%$ y $58 \%$ del costo por contribuyente lo cual resulta insuficiente. 
Tabla 1. Tasa Específica versus Costos GIRSU. Localidades seleccionadas Nodo Concordia, Paraná, Santa Elena y Municipio de San José. Año 2014

\begin{tabular}{|c|c|c|c|}
\hline \multirow[t]{2}{*}{ LOCALIDAD } & & COSTOS GIRSU & \multirow{2}{*}{$\begin{array}{l}\text { \% DE COBERTURA } \\
\text { DE LA TASA }\end{array}$} \\
\hline & $\begin{array}{l}\text { MONTO COBRADO } \\
\text { PROMEDIO ANUAL }\end{array}$ & $\begin{array}{l}\text { COSTOS PROMEDIO ANUAL } \\
\text { POR CONTRIBUYENTE }\end{array}$ & \\
\hline Paraná & $\$ 218$ & $\$ 1.659$ & $13 \%$ \\
\hline Concordia & $\$ 220$ & $\$ 1.171$ & $19 \%$ \\
\hline Santa Elena & $\$ 215$ & $\$ 819$ & $26 \%$ \\
\hline San José & $\$ 218$ & $\$ 378$ & $58 \%$ \\
\hline
\end{tabular}

Fuente: Elaboración propia en base a datos proporcionados en Plan Provincial (Secretaría de Ambiente, 2013)

Respecto de los ingresos originados en la venta de materiales recuperados la experiencia demuestra que no son relevantes (representan menos del 2 $\%$ de los recursos propios de los municipios) y si bien generan recursos estos no son suficientes para cubrir todos los costos GIRSU aun complementándose con recursos tributarios.

Tabla 2. \% de Ingresos por Venta de Material Recuperado versus Recursos Propios Municipales. Año 2013 (Valores expresado en pesos corrientes)

\begin{tabular}{|c|c|c|c|c|c|c|c|}
\hline & PARANÁ & CONCORDIA & GUALEGUAYCHÚ & CRESPO & LA PAZ & VICTORIA & ROS. DEL TALA \\
\hline Recursos Propios & $\$ 373.830 .966$ & $\$ 138.000 .000$ & $\$ 73.996 .981$ & $\$ 19.000 .000$ & $\$ 14.000 .000$ & $\$ 35.682 .690$ & $\$ 5.253 .890$ \\
\hline $\begin{array}{l}\text { Ingresos por venta } \\
\text { material recuperable }\end{array}$ & & & & & & & \\
\hline $\begin{array}{l}\text { Ingresos por materiales } \\
\text { reciclado }\end{array}$ & $\$-$ & $\$-$ & $\$ 298.968$ & $\$ 328.000$ & $\$ 21.500$ & $\$ 60.000$ & $\$ 90.000$ \\
\hline $\begin{array}{l}\text { Ingresos por material } \\
\text { compostable }\end{array}$ & $\$-$ & $\$-$ & $\$-$ & $\$-$ & $\$-$ & $\$-$ & \\
\hline Total & $\$-$ & $\$-$ & $\$ 298.968$ & $\$ 328.000$ & $\$ 21.500$ & $\$ 60.000$ & $\$ 90.000$ \\
\hline $\begin{array}{l}\% \text { material recuperable } \\
\text { respecto de los recursos } \\
\text { propios }\end{array}$ & & & $0,4 \%$ & $1,7 \%$ & $0,2 \%$ & $0,2 \%$ & $1,7 \%$ \\
\hline
\end{tabular}

Fuente: Elaboración propia en base a datos proporcionados por la Matriz para el cálculo de los costos de la gestión integral de residuos sólidos urbanos de los Municipios de Crespo, Paraná, Concordia, San José, La Paz, Rosario del Tala y Victoria. 2013

Además el mercado de reciclado es incipiente y poco desarrollado, a esto se le suma un casi nulo desarrollo de programas que estimulen el progreso en este mercado, constituyendo así una debilidad adicional respecto del objetivo de sostener la GIRSU con recursos genuinos. Por lo tanto ambas fuentes de financiamiento resultan insuficientes para alcanzar el objetivo de sostener la GIRSU. Con este panorama para contar los recursos necesarios para llevar adelante una política GIRSU se hace necesario 
un aporte complementario con fuentes de financiamientos municipales, provinciales $y / 0$ nacionales Se destaca que nivel provincial a través de la Ley 10311 — de la GRISU— crea en el Art. $32 \mathrm{el}$ «Fondo de Gestión Integral de los Residuos Sólidos Urbanos» pero aún no se ha puesto en funcionamiento, lo cual disminuye la posibilidad de contar con financiamiento provincial para la política GIRSU.

\section{Dimensión institucional}

Desde el punto de vista de la dimensión institucional de la sostenibilidad de la GIRSU se construyeron indicadores para medir y analizan los aspectos legales, recursos humanos, aspectos técnicos que caracterizan a los municipios y permiten apreciar la implementación de la política GIRSU. Para ello se realizó un relevamiento de cada uno de estos aspectos agrupándolos por rangos de municipios cuyos resultados se pueden apreciar en el Cuadro 1. En función a los resultados expuestos en dicho
Cuadro y para cada uno de los aspectos antes señalados se determinaron puntajes. A modo de ejemplo para la disponibilidad de normativa GIRSU si se toma la media de los municipios se observa el 22 $\%$ de los municipios disponen de normativa GIRSU específica, el $31 \%$ posee alguna tipo de normativa GIRSU y el $47 \%$ no posee ninguna. Para ver en cómo están posicionados cada uno de ellos se le asignó un puntaje a cada situación/variante según el siguiente detalle: los municipios que poseen normativa GIRSU el puntaje es 10 , los que cuentan con alguna normativa GIRSU 5 puntos y si no posee normativa específica 0 puntos. Dicho valores se prorratea teniendo en cuenta los porcentajes del Cuadro 1. Por ejemplo en promedio el $22 \%$ posee normativa GIRSU multiplicado por el puntaje de 10 puntos el valor ponderado arroja un valor de 2,2 puntos. En sumatoria el promedio de los municipios arroja un valor de 3,8 puntos muy por debajo de los 10 puntos que arrojaría la situación óptima.

Cuadro 1. Resumen de Indicadores Normativos, Organizacionales, Recursos Humanos y Nivel de Servicio GIRSU por Rango Municipio. Año 2016

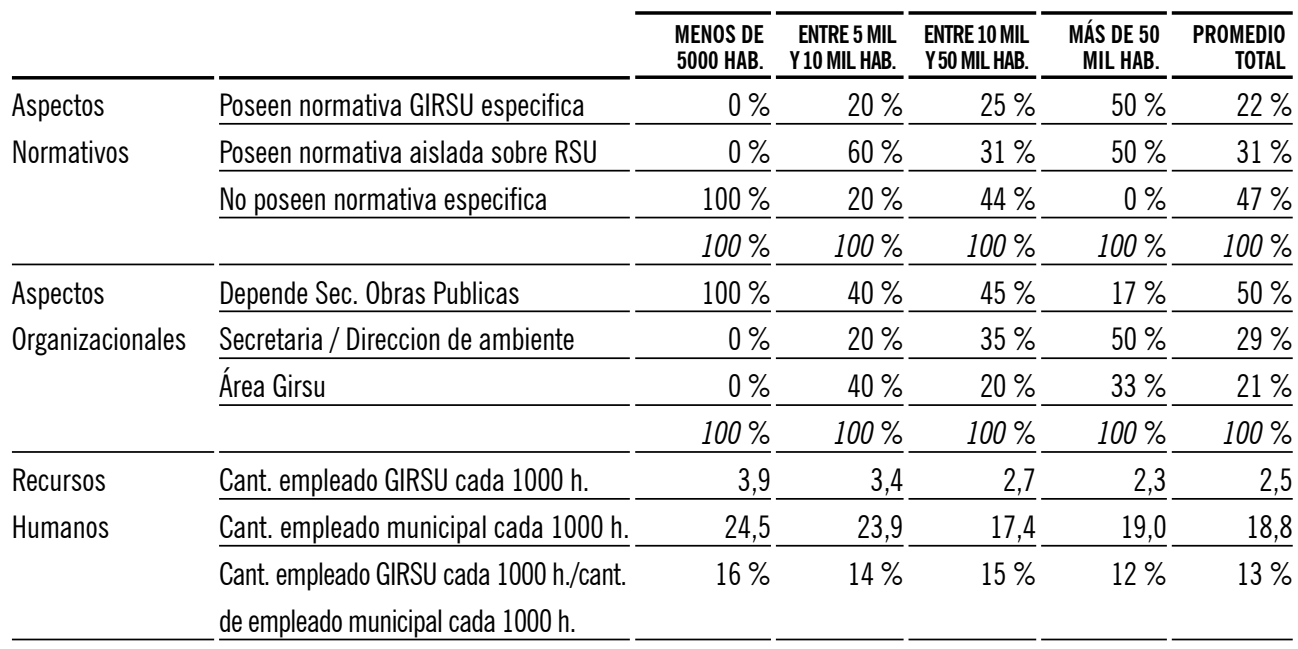

[cont. pág. sgte.] 


\begin{tabular}{|c|c|c|c|c|c|c|}
\hline & & & & & \\
\hline & & $\begin{array}{l}\text { MENOS DE } \\
5000 \mathrm{HAB} \text {. }\end{array}$ & $\begin{array}{r}\text { ENTRE } 5 \text { MLL } \\
\text { Y10 MIL HAB. } \\
\end{array}$ & $\begin{array}{l}\text { ENTRE } 10 \mathrm{MLL} \\
\text { Y } 50 \text { MLL HAB. } \\
\end{array}$ & $\begin{array}{c}\text { MÁS DE } 50 \\
\text { MIL HAB. }\end{array}$ & $\begin{array}{r}\text { PROMEDIO } \\
\text { TOTAL } \\
\end{array}$ \\
\hline \multicolumn{7}{|c|}{ Nivel servicio GIRSU [continuación] } \\
\hline \multirow[t]{3}{*}{ Barrido } & Con servicios (manual y/o mecánico) & $83 \%$ & $100 \%$ & $100 \%$ & $100 \%$ & $97 \%$ \\
\hline & Sin servicio & $17 \%$ & $0 \%$ & $0 \%$ & $0 \%$ & $3 \%$ \\
\hline & & $100 \%$ & $100 \%$ & $100 \%$ & $100 \%$ & $100 \%$ \\
\hline \multirow[t]{8}{*}{ Recolección } & Separación en origen & $17 \%$ & $60 \%$ & $50 \%$ & $75 \%$ & $48 \%$ \\
\hline & Convencional & $83 \%$ & $40 \%$ & $50 \%$ & $25 \%$ & $52 \%$ \\
\hline & & $100 \%$ & $100 \%$ & $100 \%$ & $100 \%$ & $100 \%$ \\
\hline & $\underline{\text { Separación en origen }}$ & & & & & \\
\hline & Cobertura mayor 50 \% de población & $0 \%$ & $100 \%$ & $38 \%$ & $33 \%$ & $47 \%$ \\
\hline & $\begin{array}{l}\text { Cobertura entre el } 50 \text { \% y } 30 \text { \% } \\
\text { de población }\end{array}$ & $100 \%$ & $0 \%$ & $13 \%$ & $0 \%$ & $13 \%$ \\
\hline & Cobertura menor al $30 \%$ de la pob & $0 \%$ & $0 \%$ & $50 \%$ & $67 \%$ & $40 \%$ \\
\hline & & $100 \%$ & $100 \%$ & $100 \%$ & $100 \%$ & $100 \%$ \\
\hline Planta de & Existencia de Plantas & & & & & \\
\hline \multirow[t]{7}{*}{ separación } & $\underline{\mathrm{Si}}$ & $67 \%$ & $60 \%$ & $78 \%$ & $75 \%$ & $73 \%$ \\
\hline & № & $33 \%$ & $40 \%$ & $22 \%$ & $25 \%$ & $27 \%$ \\
\hline & & $100 \%$ & $100 \%$ & $100 \%$ & $100 \%$ & $100 \%$ \\
\hline & Estado de las Plantas & & & & & \\
\hline & bueno & $50 \%$ & $67 \%$ & $42 \%$ & $0 \%$ & $42 \%$ \\
\hline & regular & $50 \%$ & $33 \%$ & $58 \%$ & $100 \%$ & $58 \%$ \\
\hline & & $100 \%$ & $100 \%$ & $100 \%$ & $100 \%$ & $100 \%$ \\
\hline \multirow[t]{3}{*}{ Disposición Final } & Basural a cielo abierto & $83 \%$ & $80 \%$ & $67 \%$ & $50 \%$ & $70 \%$ \\
\hline & Vertedero controlado/celda impermeable & $17 \%$ & $20 \%$ & $33 \%$ & $50 \%$ & $30 \%$ \\
\hline & & $100 \%$ & $100 \%$ & $100 \%$ & $100 \%$ & $100 \%$ \\
\hline Separación & $\underline{\mathrm{Si}}$ & $33 \%$ & $100 \%$ & $76 \%$ & $100 \%$ & $75 \%$ \\
\hline \multirow[t]{2}{*}{ informal } & № & $67 \%$ & $0 \%$ & $24 \%$ & $0 \%$ & $25 \%$ \\
\hline & & $100 \%$ & $100 \%$ & $100 \%$ & $100 \%$ & $100 \%$ \\
\hline
\end{tabular}

Fuente: Elaboración propia en base a datos proporcionados por el plan provincial y Municipios (Secretaría de Ambiente, 2013)

Tabla 3. Categorización por Rango de Municipios según Disponibilidad de Normativa en Materia de Gestión de RSU. Año 2016

\begin{tabular}{|c|c|c|c|c|}
\hline & \multirow[b]{2}{*}{$\begin{array}{l}\text { POSEEN } \\
\text { NORMATIVA } \\
\text { GIRSU } \\
\end{array}$} & \multirow[b]{2}{*}{$\begin{array}{l}\text { POSEEN ALGU- } \\
\text { NA NORMATIVA } \\
\text { GIRSU }\end{array}$} & \multirow[b]{2}{*}{ NO POSEEN } & \multirow[b]{2}{*}{$\begin{array}{l}\text { PUNTAJE } \\
\text { TOTAL }\end{array}$} \\
\hline & & & & \\
\hline Puntaje máximo & 10 & 5 & 0 & \\
\hline Menos de 5000 habitantes & - & - & - & 0 \\
\hline Entre 5 mil y 10 mil habitantes & 2,0 & 3,0 & _ & 5,0 \\
\hline Entre 10 mil y 50 mil habitantes & 2,5 & 1,6 & _ & 4,1 \\
\hline Más de 50 mil habitantes & 5,0 & 2,5 & 二 & 7,5 \\
\hline Prom & 2,2 & 1,6 & - & 3,8 \\
\hline
\end{tabular}

Fuente: Elaboración propia 
Respecto de los aspectos organizacionales se tuvo en cuenta si el municipio dispone de una estructura administrativa en el área específica para realizar la gestión de la GIRSU. En promedio el 21 $\%$ de los municipios cuentan con áreas o dependencias especificas GIRSU, el $29 \%$ cuenta con una Secretaría o Dirección de Ambiente y el 50 \% directamente no disponen de áreas específicas y las actividades se desarrollan a través de la Secretaría de Obras Públicas. El puntaje promedio de los municipios arroja un valor de 4,6 puntos muy por debajo del óptimo del puntaje máximo (10 puntos).

Tabla 4. Categorización por rango de Municipios según la estructura orgánica. Año 2016

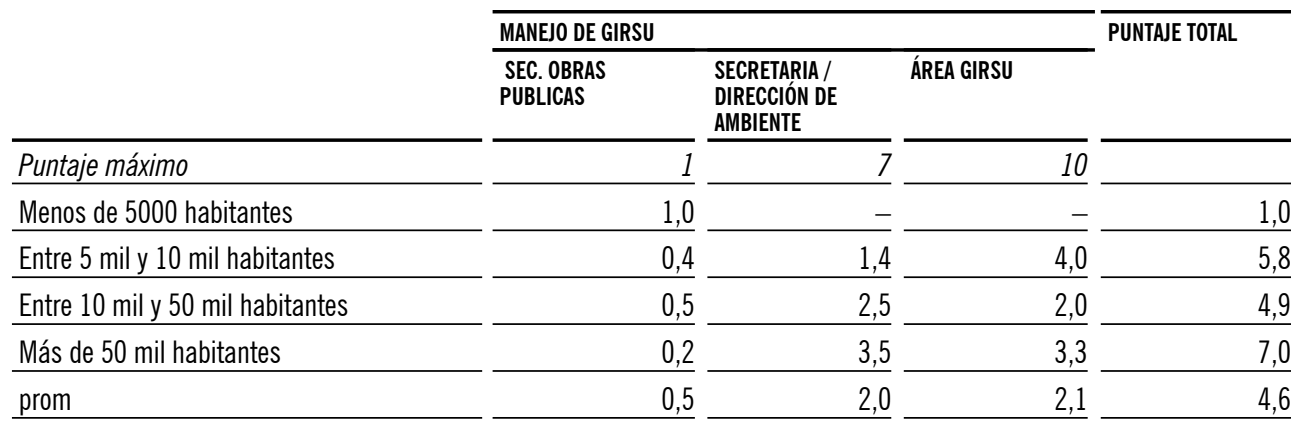

Fuente: Elaboración propia en base a datos del Cuadro 1

Respecto de los recursos humanos tiene en cuenta la cantidad de empleados utilizados para la actividad GIRSU en relación con población, y también la correspondencia de estos respecto de la cantidad de empleados promedio dispuestos por los municipios para diferentes actividades. El primer indicador marca que, en promedio, los municipios entrerrianos destinan 2,5 servidores públicos a realizar la gestión de RSU y estos trabajadores representan el $13 \%$ de los empleados municipales (ver Cuadro 1). Si el puntaje se determina adoptando el criterio de fijarle a la media 5 puntos y a cada uno de estos indicadores ${ }^{2}$ se los pondera con un peso del $50 \%$, el resultado de la media provincial dará un puntaje promedio ponderado de 5 puntos. Luego los municipios cuyos indicadores tienen un valor más alto que la media se les otorga un puntaje mayor y a la inversa si los valores son menores.

(2) Respecto del ler indicador hace referencia a la Cantidad de empleados GIRSU cada 1000 hab. y el segundo a la proporción de empleado GIRSU en relación con el total de empleados municipales 
Tabla 5. Categorización por Rango de Municipios según la Disponibilidad de Recursos Humanos. Año 2016

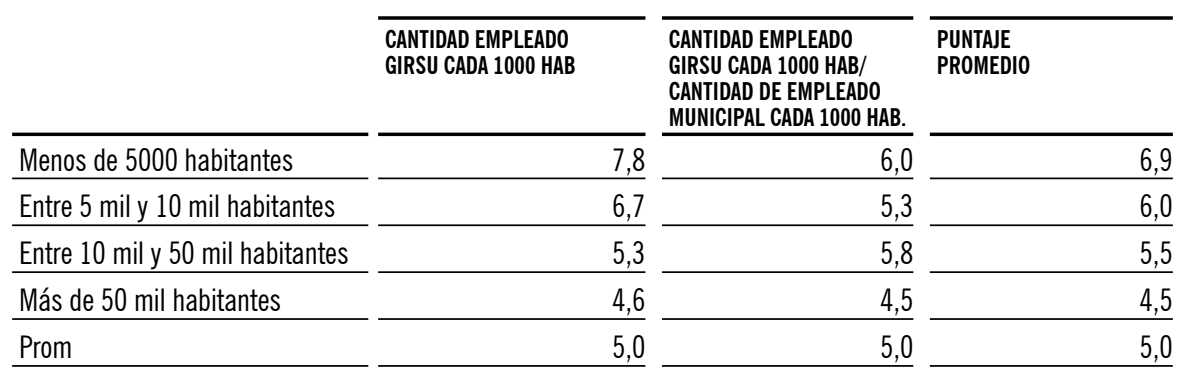

Fuente: Elaboración propia en base a datos del Cuadro 1

Para analizar el nivel de servicio brindado en cada etapa de la GIRSU — barrido y limpieza, recolección, separación y disposición final- a continuación se detallan los indicadores seleccionados.

Para la etapa de barrido y limpieza se utiliza como indicador si los Municipios disponen o no de este servicio. En promedio el $97 \%$ de los municipios brindan el servicio y solo un $3 \%$ no. El puntaje ponderado arroja un valor de 9,7 puntos lo que muestra una gran cantidad de localidades que prestan el servicio.

Tabla 6. Categorización por rango de Municipios según la Disponibilidad de Servicio de Barrido y Limpieza Año 2016

\begin{tabular}{|c|c|c|c|}
\hline & $\begin{array}{l}\text { CON SERVICIOS (MANUAL } \\
\text { Y/O MECÁNICO) }\end{array}$ & $\begin{array}{l}\text { SIN } \\
\text { SERVICIO }\end{array}$ & PUNTAJE PROMEDIO \\
\hline Puntaje máximo & 10 & 0 & \\
\hline Menos de 5000 habitantes & 8,3 & - & 8,3 \\
\hline Entre 5 mil y 10 mil habitantes & 10,0 & - & 10,0 \\
\hline Entre 10 mil y 50 mil habitantes & 10,0 & _ & 10,0 \\
\hline Más de 50 mil habitantes & 10,0 & - & 10,0 \\
\hline prom & 9,7 & - & 9,7 \\
\hline
\end{tabular}

Fuente: Elaboración propia en base a datos del Cuadro 1

Respecto de la recolección se utilizan dos indicadores el primero es el tipo de servicio brindado, diferenciándose entre separación en origen y recolección convencional, y el segundo tiene en cuenta para el servicio de separación en origen el porcentaje de cobertura de la población.

Según el Cuadro 1 en promedio el $48 \%$ de los municipios separan en origen y en un $52 \%$ se recolecta de manera convencional. De los municipios que realizan separación en origen el 47 \% tienen una cobertura mayor al $50 \%$ de la población, un $13 \%$ cubre entre un $50 \%$ y $30 \%$, y un $40 \%$ abarca menos del 30 $\%$. Se asignó un puntaje de 10 para la separación en origen y 5 a la recolección convencional, al puntaje de la separación en origen se le apropia un porcentaje ponderado en función a la cobertura utilizando un puntaje de 10, 5 y 3 puntos. El puntaje promedio de los municipios arroja un valor de 5,7 puntos lo que muestra un nivel de prestación del servicio aceptable. 
Tabla 7. Categorización por rango de Municipios según la disponibilidad de Servicio de Recolección Año 2016

\begin{tabular}{|c|c|c|c|c|c|c|c|c|c|}
\hline & \multirow{2}{*}{\multicolumn{3}{|c|}{ TIPO DE SEPARACIÓN }} & & & & & & \\
\hline & & & & \multicolumn{5}{|c|}{ \% DE COBERTURA SEPARACIÓN EN ORIGEN } & \multirow{2}{*}{$\begin{array}{l}\text { PUNTAJE } \\
\text { PROM }\end{array}$} \\
\hline & $\begin{array}{l}\text { SEPARA- } \\
\text { CION EN } \\
\text { ORIGEN }\end{array}$ & $\begin{array}{l}\text { CONVEN- } \\
\text { CIONAL }\end{array}$ & PUNTAJE & $>50 \%$ & $\begin{array}{l}\text { EN } 30 \% \\
\text { Y } 50 \%\end{array}$ & $<30 \%$ & $\begin{array}{l}\text { PUNTAJE } \\
\end{array}$ & $\begin{array}{l}\text { \% APRO- } \\
\text { PIACIÓN } \\
\text { PUNTAJE } \\
\end{array}$ & \\
\hline Puntaje máximo & 10 & 5 & & 10. & 5 & 3 & & & \\
\hline Menos de 5000 hab & 1,7 & 4,2 & 5,8 & - & 5,0 & - & 5,0 & $50 \%$ & 5,0 \\
\hline Entre 5 mil y 10 mil hab & 6,0 & 2,0 & 8,0 & 10,0 & - & - & 10,0 & $100 \%$ & 8,0 \\
\hline Entre 10 mil y 50 mil hab & 5,0 & 2,5 & 7,5 & 3,8 & 0,6 & 1,5 & 5,9 & $59 \%$ & 5,4 \\
\hline Más de 50 mil hab & 7,5 & 1,3 & 8,8 & 3,3 & - & 2,0 & 5,3 & $53 \%$ & 5,3 \\
\hline prom & 4,8 & 2,6 & 7,4 & 4,7 & 0,7 & 1,2 & 6,5 & $65 \%$ & 5,7 \\
\hline
\end{tabular}

Fuente: Elaboración propia en base a datos del Cuadro 1

Para la etapa de separación el indicador que se utiliza es la disponibilidad o no de la infraestructura necesaria —Planta de Separación y Clasificación PSyC — para realizar el trabajo de separación de los residuos y el estado en que se encuentra dicha infraestructura. En promedio el $73 \%$ de los municipios cuentan con PSyC y el $27 \%$ no. De los municipios que disponen de la infraestructura el 42 \% está en buen estado y el 58 \% la condición del equipamiento es regular. Se asignó un puntaje de 10 para los que disponen de la infraestructura y $0 \mathrm{a}$ los que no, ponderado por el porcentaje de municipios. Este puntaje se ve reducido por el estado de la infraestructura llegando de esta manera al puntaje final promedio de los municipios con un valor de 3,8 puntos bastante alejado del óptimo que es de 10 puntos. En nivel general de los municipios es regular en este aspecto.

Tabla 8. Categorización por rango de Municipios según la Disponibilidad Servicio de Separación Año 2016

\begin{tabular}{|c|c|c|c|c|c|c|c|}
\hline & \multirow{2}{*}{\multicolumn{3}{|c|}{ EXISTENCIA DE PLANTAS DE SEPARACIÓN }} & \multirow{2}{*}{\multicolumn{3}{|c|}{ ESTADO DE LA PLANTAS DE SEPARACIÓN }} & \multirow{3}{*}{$\begin{array}{l}\text { PUNTAJE } \\
\text { PROMEDIO }\end{array}$} \\
\hline & & & & & & & \\
\hline & SI & No & BUENO & REGULAR & PUNTAJE & $\begin{array}{l}\text { \%APROPIA- } \\
\text { CIÓN PUNTAJE }\end{array}$ & \\
\hline Puntaje máximo & 10 & 0 & 7 & 4 & & & \\
\hline Menos de 5000 hab & 6,7 & _ & 3,5 & 2,0 & 5,5 & $55 \%$ & 3,7 \\
\hline Entre 5 mil y 10 mil hab & 6,0 & - & 4,7 & 1,3 & 6,0 & $60 \%$ & 3,6 \\
\hline Entre 10 mil y 50 mil hab & 7,8 & - & 2,9 & 2,3 & 5,3 & $53 \%$ & 4,1 \\
\hline Más de 50 mil hab & 7,5 & - & - & 4,0 & 4,0 & $40 \%$ & 3,0 \\
\hline prom & 7,3 & - & 2,9 & 2,3 & 5,3 & $53 \%$ & 3,8 \\
\hline
\end{tabular}

Fuente: Elaboración propia en base a datos del Cuadro 1

Para la disposición final se toma como indicador el tipo de servicio que se brinda en cada municipio distinguiéndose aquellos que disponen los residuos sin ningún tipo de tratamiento en basurales a cielo abierto y los que los que colocan en un sitio de disposición final (SDF) con algún tipo de tratamiento (vertedero o celda de impermeabilización). En promedio el $70 \%$ de los municipios disponen los 
residuos a cielo abierto y solo un $30 \%$ tienen SDF con algún tipo de tratamiento. Se asigno un puntaje de 10 para los que realizan tratamiento al SDF y 0 a los disponen los residuos a cielo abierto y luego se los pondera por el porcentaje de municipios. El puntaje final promedio de los municipios asciende a
3 puntos muy por debajo del optimo (10 puntos). Se destacan los municipios grandes que tiene el $50 \%$ de SDF con algún tipo de tratamiento por tal motivo se le asigna un puntaje de 5 , mientras que el resto tienen un puntaje regular a malo.

Tabla 9. Categorización por Rango de Municipios según la Disponibilidad de Servicio de Disposición Final Año 2016

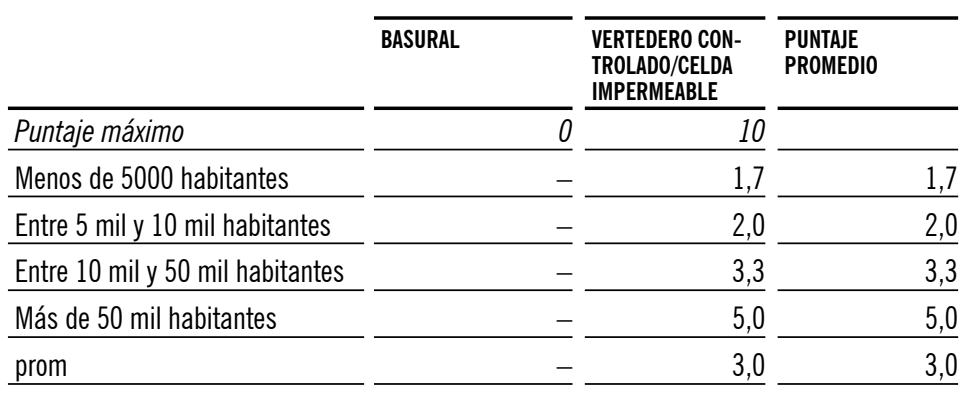

Fuente: Elaboración propia en base a datos del Cuadro 1

Para determinar el puntaje que los municipios obtienen por la gestión integral de la RSU se propone fijar a cada una de las etapas un peso relativo en función a la contribución que estas hacen al mejoramiento de la gestión RSU. Se le atribuye el menor peso relativo a la etapa de barrido, solo un $5 \%$, por considerarse la etapa mejor gestionada y el $95 \%$ restante se lo distri- buyo equitativamente al resto de las etapas (recolección, separación y disposición final) asignándole un peso del 32 \% cada una. Posteriormente se multiplica el puntaje fijado a cada escala de municipio por el peso asignado a cada etapa y en la columna de valor ponderado se obtiene el puntaje final. El puntaje ponderado del promedio de los municipios arriba a un valor de 4,5 puntos.

Tabla 10. Asignación de Puntaje Ponderado por Rango de Municipio de la Gestión RSU Año 2016

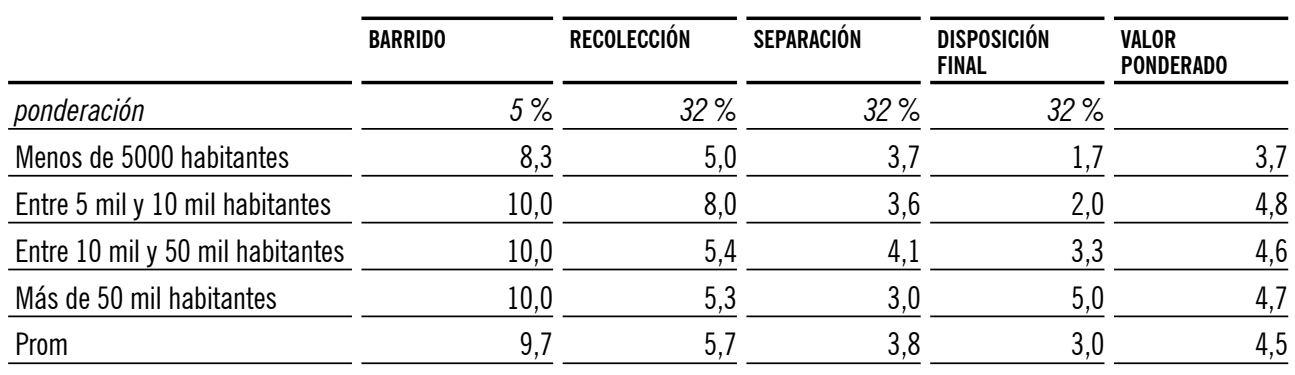


Por último en los aspectos sociales se diferenciaron los municipios que cuentan con recuperadores informales trabajando en la localidad de los que no. Para ello se adopta el supuesto que la existencia de recuperadores informales implica una falta de respuesta en la política social municipal. En promedio el $75 \%$ de los municipios cuentan con recuperadores infor- males en sus localidades y el $25 \%$ restante no. Se asignó un puntaje de 10 a los municipios que no tiene recuperadores informales en sus localidades y 0 a los que tienen. El puntaje final promedio de los municipios asciende a 2,5 puntos muy por debajo del optimo (10 puntos).

Tabla 11. Categorización por rango de Municipios según la disponibilidad de Recolección Informal de Residuos Año 2016

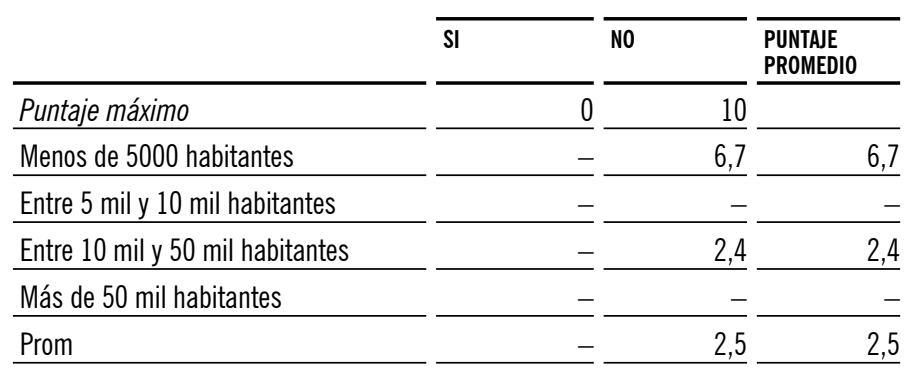

Fuente: Elaboración propia en base a datos del Cuadro 1

Para realizar la evaluación de los distintos aspectos tabla que se expone a continuación los puntajes obterelevados en una primera instancia se resume en la nidos en los análisis realizados párrafos anteriores.

Tabla 12. Asignación de Puntaje de Aspectos Relevantes de la Sostenibilidad Institucional por Rango Municipio Año 2016

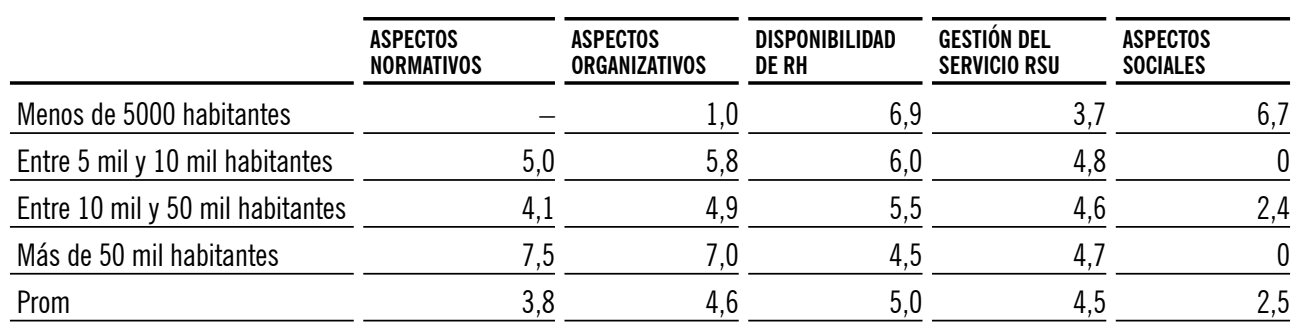

Fuente: Elaboración propia 
Esta tabla permite aprecia que los aspectos normativos y sociales son los que disponen en promedio el menor puntaje y más se alejan del optimo (10 puntos), el resto de los aspectos analizados se encuentran en torno a los 5 puntos valor que es aceptable pero refleja que se deben mejorar los aspectos organizativos, de gestión del servicio de RSU y la disponibilidad de recursos humanos (RH).

Ilustración 5. Indicadores de Sostenibilidad Institucional- Promedio Municipios de Prov. Entre Ríos

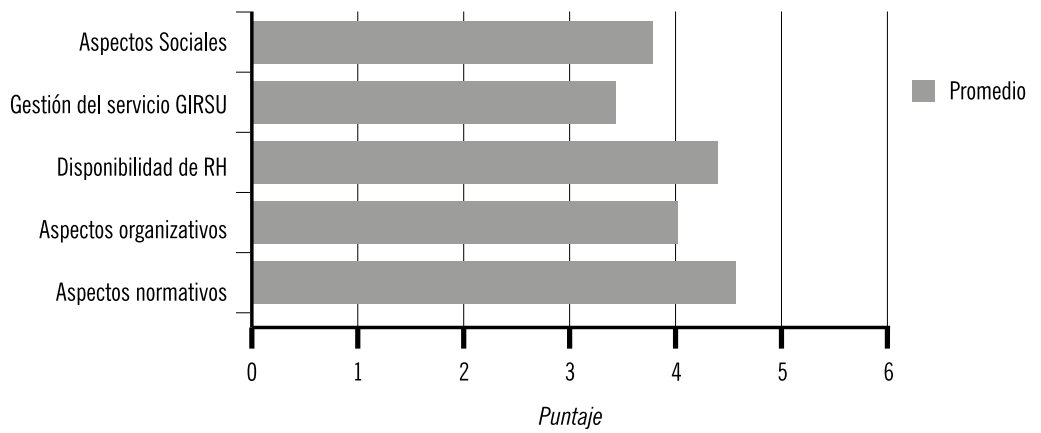

Fuente: Elaboración propia

Estos indicadores muestran dos cuestiones centrales, la primera de ella es la identificación de las fortalezas y debilidades de la sostenibilidad institucional. Dentro de las fortalezas se encuentran los aspectos relacionados con organización administrativa, gestión de la RSU y disponibilidad de recursos humanos. Si bien los mismos se encuentran muy lejos del óptimo se verifica que los municipios están trabajando en un nivel medio pero destacando que es necesario mejorar muchas cuestiones. Respecto de las debilidades se marcan como las principales los aspectos normativos y sociales encontrándose allí pocos avances. La segunda cuestión que permiten constatar estos indicadores es la heterogeneidad visualizada en las diferentes escalas municipales motivada por las distintas capacidades instit ucionales dificultando la implementación de la política.

Ello hace pensar que el diseño del plan tiene deficiencias en formulación de la dimensión económica e institucional identificando al financiamiento insuficiente y a los aspectos sociales como las cuestiones más influentes de manera negativa en la sostenibilidad de la política. Además se marcan la falta de estrategias de implementación en los aspectos normativos y administrativos, los cuales influyen sustancialmente en la materialización y la implementación de las propuestas. Las herramientas diseñadas en el plan contribuyen parcialmente a la sostenibilidad en el tiempo de las políticas ambientales.

\section{Conclusiones}

Al describir y analizar la política GIRSU se arriban a las siguientes conclusiones respecto de los diferentes objetivos definidos y las hipótesis planteadas.

En relación con el análisis del diseño de la política GIRSU propuesta en el Plan Provincial se evaluaron los criterios integralidad, coherencia y coordinación.

Respecto del criterio de integralidad se observa que el abordaje de la problemática GIRSU tomó en cuenta sus múltiples dimensiones, tanto los aspectos sociales, económicos, y ambientales, 
como las políticas institucionales de la gestión de residuos en los municipios. No obstante, a la hora de la formulación de los proyectos, si bien se describen aspectos técnicos, ambientales, legales y económicos a ser tenidos en cuenta en la implementación, el énfasis está puesto en la materialización física del proyecto (incorporación de camiones recolectores, adquisición de planta de separación de residuos e instalación del sitio disposición final). $\mathrm{Y}$, como resultado, no se consideran relevantes los aspectos sociales, educacionales, comunicacionales y organizativos que concurren a la generación de la problemática que se procura remediar. Este sesgo metodológico inhibe el enfoque integral en el diseño de la política y reduce tanto el análisis como la evaluación con lo cual se pierde eficacia y eficiencia en la implementación.

En referencia al criterio de coherencia, se exploraron los aspectos internos y externos de la política diseñada en el Plan GIRSU. En referencia a la coherencia interna se compararon, para cada uno de los objetivos planteados en la formulación de la política, las líneas de acción y actividades previstas al respecto. Se observa aquí que éstas no resultan coherentes en muchos de los casos. Así, por ejemplo, la definición de la forma de financiar las actividades previstas para concretar los objetivos no resulta clara y no detalla los instrumentos a utilizar. Existen además actividades superpuestas en distintas líneas de acción lo que genera perdida de eficiencia en el uso de los recursos. Estas inconsistencias son relevantes a la hora de implementar la política y redundan en la falta de eficacia y eficiencia en el logro de los objetivos.

En lo relativo a la coherencia externa se puede apreciar que hay cierta congruencia entre los contenidos diseñados para la política GIRSU y los objetivos definidos en las jurisdicciones provinciales. Esta situación no se repite en el diseño de las políticas a implementarse en las jurisdicciones locales donde hay incertidumbre sobre su aplicación debido a la autonomía jurídica de las localidades y de los tiempos que le lleve a materializar dicha política. Además, para los casos en que exista voluntad institucional y política de acompañar las propuestas provinciales y nacionales, implica la gestión y resolución de acuerdos formales que demandan compromisos legislativos locales que suponen tiempos y situaciones no gobernables para los responsables de la ejecución del Programa en el orden nacional y provincial

Por último en relación con el principio de Coordinación, puede señalarse desde el punto de vista horizontal intersectorial la Secretaria de Ambiente lleva adelante una gestión de la política ambiental que resulta transversal a las distintas jurisdicciones administrativas que conforman el gobierno provincial. En el mismo sentido se observa en lo organizativo - institucional la inexistencia de solapamientos 0 duplicaciones innecesarias de unidades administrativas (que cumplan funciones similares 0 que dupliquen esfuerzos al interior de un mismo sector) Si se aprecia en el ámbito operativo de las políticas un cierto grado de interacción y sinergia con otros organismos provinciales aunque aún muy incipiente. En relación con la coordinación entre distintos niveles de gobierno — plano vertical interjurisdiccionalse aprecia una importante y fluida coordinación con el nivel nacional-provincial. Pero en la relación provincia-municipio encuentra la mayor debilidad por la escasa institucionalidad y reconocimiento otorgado por los Municipios y Comunas al ámbito de gestión y acuerdos sobre la política de GIRSU. Por otro lado Ios actores no estatales directamente no cuentan con un ámbito formal donde discutir esta política aunque si hay una interacción informal sobre todo en los ámbitos municipales. Estas últimas dos cuestiones limitan la aplicación de los diseños de políticas, planes, programas y acciones propuestos en el nivel nacional y provincial en los niveles locales, y estos termina reconfigurando dichas políticas en la medida que son implementadas y ejecutadas de acuerdo con sus agendas particulares.

Cuando se verifica el grado de correspondencia de los objetivos formulados por la normativa nacional en la medida que se replican en niveles 
estatales jerárquicamente inferiores se puede apreciar que a nivel provincial la normativa y estrategias definidas son congruentes con las definidas por el nivel nacional. A nivel local se observa un bajísimo porcentaje de municipios que han adaptado su normativa a las definidas a nivel nacional y provincial, ya que los municipios que no disponen de normativa GIRSU 0 disponen de normativa asilada representan un $74 \%$ de la muestra. De los municipios que si poseen normativa GIRSU se puede apreciar que son coherentes y congruentes con las normas definidas a nivel nacional y provincial, pero se advierte un bajo nivel de implementación de la normativa local en acciones concretas.

Posteriormente se evalúa la incidencia de la heterogeneidad de las capacidades institucionales locales en el grado de cumplimiento de las expectativas de los programas y proyectos. Para ello se estudian aspectos institucionales, ambientales y sociales de la provincia y los distintos municipios entrerrianos. De las situaciones locales se puede verificar que capacidad de gestión de los residuos tiene una disparidad muy importante, lo mismo ocurre con el nivel de servicio brindado por cada municipio y ello esta impactado por las pautas culturales de la población. Esta heterogeneidad no se ve registrada de manera adecuada en el diseño del Plan Provincial y esto conspira contra una implementación eficaz, reducen el nivel de logro de metas y objetivos. Esto hace que los municipios reconfiguren sus objetivos por debajo de los estándares definidos en la el Plan verificándose con una de las hipótesis planteada para el presente trabajo.

Por último se verifica la sostenibilidad intertemporal de las políticas diseñadas. Desde el punto de vista de la dimensión económica quedan en evidencia los problemas que tienen los municipios para financiar la GIRSU. Los recursos provenientes de fuentes tributarias cubren en la actualidad parcialmente la gestión actual de residuos y de implementarse el cobro de una tasa específica tampoco lograría abarcar la totalidad de los costos del servicio. Respecto de los ingresos originados en la venta de materiales recuperados la experiencia demuestra no son relevantes y si bien generan recursos estos no son suficientes para cubrir todos los costos GIRSU aun complementándose con recursos tributarios. Además el mercado de reciclado es incipiente y poco desarrollado, a esto se le suma un casi nulo desarrollo de programas para estimular el progreso de este mercado, lo cual se considera una debilidad en el diseño de la política. Para hacer sostenible desde el punto de vista económico la política GIRSU se hace necesario un aporte complementario de fuentes de financiamientos municipales, provinciales y/o nacionales.

Desde el punto de vista de la dimensión institucional de la sostenibilidad de la GIRSU se construyeron indicadores para medir y analizan los aspectos legales, recursos humanos, aspectos técnicos que caracterizan a los municipios y permiten apreciar la implementación de la política GIRSU. Estos indicadores muestran como fortalezas los aspectos relacionados con organización administrativa, la gestión de la RSU y disponibilidad de recursos humanos, aunque con muchos aspectos por mejorar. Respecto de las debilidades se marcan como las principales los aspectos normativos y sociales encontrándose allí pocos avances. Otra cuestión que permiten visualizar estos indicadores es la heterogeneidad observada en las diferentes escalas municipales motivada por las distintas capacidades institucionales dificultando la implementación de la política.

Ello hace pensar que el diseño del Plan contribuye parcialmente en la formulación de herramientas para lograr a la sostenibilidad en el tiempo de las políticas GIRSU.

De la revisión realizada anteriormente se fueron confirmando la mayoría de las hipótesis planteas lo que lleva a pensar en la necesidad de una nueva revisión del diseño a fin de incluir todos los aspectos que fueron «recortados» a la hora de formular la política. 


\section{Referencias bibliográficas}

- Acuña, C. (2010). Los desafíos de la Coordinación y la Integralidad para las Políticas y la Gestión Pública en América Latina. Una Introducción. Proyecto de Modernización del Estado Jefatura de Gabinete de Ministros de la Nación. Recuperado en julio 2017 de http:// www.jefatura.gob.ar/archivos/pme/publicaciones/desafios_coordinacion.pdf - Bueno Suárez, C., y Osuna Llaneza, J.L. (2013, Octubre). Evaluación del diseño de políticas públicas: propuesta de un modelo integral. Revista del CLAD Reforma y Democracia, 57, 37-66.

- Cohen, E., y Franco, R. (2005). Gestión social: cómo lograr eficiencia e impacto en las políticas sociaIes. México: CEPAL. Silgo XXI editores - Gligo, N. (1997). Institucionalidad pública y políticas ambientales explícitas e implícitas. Revista de la CEPAL, 63, 51-65. - Gutiérrez, R.A., e Isuani, F. (2013). Luces y sombras de la política ambiental argentina entre 1983 y 2013. Revista SAAP, 7, 317-328. Recuperado de http://www.scielo.org.ar/scielo. php? script $=$ sci_arttext\&pid $=\$ 1853$ $19702013000200010 \& \operatorname{lng}=e s \& n r m=i s 0$ - Isuani, F. (2013). Institucionalidad Ambiental en la Provincia de Buenos Aires (1983-2011). Desafíos a la coherencia, integralidad y coordinación. Trabajo preparado para el VII Congreso Argentino de Administración Pública «Liderazgo, Equidad y Sustentabilidad». Mendoza, 18, 19 y 20 de septiembre 2013. Recuperado en enero 2017 de http:// www.ungs.edu.ar/ms ico/wp-content/ uploads/2014/10/Pol \%C3 \%ADticaAmbiental-en-la-Provincia-de-Buenos-Aire-Isuani-20131.pdf

- Jaime, F.M., Dufour, G., Alessandro, M., y Amaya, P. (2013). Capítulo III: Las Políticas Públicas: el desarrollo de un campo disciplinar y Capítulo IV: El proceso de las políticaspúblicas. En
F.M. Jaime, G. Dufour, M. Alessandro y P. Amaya, Introducción al análisis de las políticas públicas. Florencio Varela: Universidad Nacional Arturo Jaureche. - Lerda, J.C., Acquatella, J., y Gómez, J.J. (2003). Integración, coherencia y coordinación de Políticas Públicas Sectoriales (reflexiones para el caso de las políticas fiscal y ambiental). CEPAL, Revista Series medio ambiente y desarrollo, 76 . Recuperado en enero 2017 de http:// repositorio.cepal.org/bitstream/ handle/11362/5778/S0311862 es.pdf? sequence $=1$

- Ley Nro. 25.916/2004, Gestión de Residuos Domiciliarios, Boletín Oficial de la República Argentina, 07 de septiembre de 2004. Recuperado en enero 2017 de http://servicios. infoleg.gob.ar/infolegInternet/anexos/95000-99999/98327/norma.htm

- Ley Provincial Nro. 10.311/2014, Gestión integral de los residuos sólidos urbanos, Boletín oficial de la Provincial de Entre Ríos, 23 de Junio de 2014.

- Martínez Nogueira, R. (2010). Los Desafíos de la Coordinación y la Integralidad de las Políticas y Gestión Pública en América Latina. La Coherencia y la Coordinación de las Políticas Públicas. Aspectos Conceptuales y Experiencias. Proyecto de Modernización del Estado Jefatura de Gabinete de Ministros de la Nación. Recuperado en enero 2017 de http://www. jefatura.gob.ar/archivos/pme/publicaciones/desafios_coordinacion.pdf - Repetto, F. (2005). La dimensión política de la coordinación de programas y políticas sociales: una aproximación teórica y algunas referencias prácticas en América Latina. En F. Repetto (ed.), La gerencia social ante los nuevos retos del desarrollo social en América Latina. Ciudad de Guatemala: INDES-Guatemala.
- Repetto, F., y Fernández, J.P. (2012). Coordinación de políticas, programas y proyectos sociales. Buenos Aires: CIPPEC y UNICEF.

- Sarlingo, M. (2004). iSer "verdes" o parecer "verdes"? Conflicto y reproducción: la política ambiental de la Provincia de Buenos Aires en los años '90 (Tesis doctoral). Facultad de Filosofía y Letras, Universidad de Buenos Aires, Argentina.

- Secretaría de Ambiente Provincia de Entre Ríos. (2013). Documento: Plan Provincial de Gestión Integral de Residuos Urbanos (GIRSU) de Entre Ríos. Recuperado en febrero 2017 de https://www.entrerios.gov.ar/ambiente/index.php?codig $0=77 \&$ codsubmen $\mathrm{u}=87$ \&menu $=$ menu\&modulo $=$

- Secretaría de Ambiente y DesarroIlo Sustentable de Argentina (SAyDS). (2004). Documento: Bases de una agenda orientada a una Política Ambiental Sostenible para el Crecimiento y la Equidad. Recuperado en febrero 2017 de http://publicaciones.ops. org.ar/publicaciones/cdsMCS/05/ pub_msan/base_agenda.pdf

- Secretaría de Ambiente y DesarroIlo Sustentable de Argentina (SAyDS). (2005). Documento: Estrategia Nacional para la Gestión Integral de Residuos Sólidos Urbanos (ENGIRSU). Recuperado en febrero 2017 de http://www.ambiente.gov.ar/observatoriorsu/infoteca/ archivos_para_bajar/ENGIRSU.pdf

- Tamayo Sáez, M. (1997). Capítulo 11: El Análisis de las Políticas Públicas. En R. Bañón y E. Carrillo (Comp.), La nueva administración pública (pp. 281312). Madrid: Alianza Universidad.

\section{Registro bibliográfico}

Bach, M. (2017). Articulación interestatal en la gestión de residuos sólidos urbanos. El caso de los Municipios entrerrianos. Revista Ciencias Económicas, 14(01), 45-74. 